\title{
OBSERVANDO EL HOGAR. VIDA COTIDIANA Y REALIDAD MATERIAL DOMÉSTICA DE LOS MORISCOS DE CASTILLA. 1570-1610*
}

\author{
Francisco J. Moreno Díaz del Campo**
}

De unos años a esta parte, un amplio sector de la historiografía española ha centrado sus esfuerzos en analizar el mundo de lo cotidiano. Hoy son muy visibles los nexos que ese enfoque mantiene con la historia cultural, abordando aspectos que van desde las costumbres y la religiosidad popular hasta la alimentación, el juego, el mundo del trabajo no reglado o las actividades de recreo y esparcimiento. Se trata de una línea de investigación fecunda que, en España, cuenta con cierta tradición (incluso autóctona) ${ }^{1}$. Sin embargo, y como en tantas otras facetas relativas al reciente devenir de nuestra disciplina, se asentó como resultado de la innegable influencia que ejerció la historiografía francesa en el tramo final del siglo XX. Desde entonces, ha ofrecido interesantes resultados gracias a una ímproba labor de documentación y archivo. En la consolidación de ese crecimiento también ha tenido mucho que ver el diálogo que los historiadores han mantenido con investigadores procedentes de la Filosofía, la Antropología, la Arqueología o la Historia del Arte.

* La elaboración del artículo que sigue ha sido posible gracias a la Ayuda a la Investigación para Temas Mudéjares y Moriscos (año 2015) del Centro de Estudios Mudéjares (Instituto de Estudios Turolenses) concedida al proyecto Cultura material y vida cotidiana de los moriscos de Castilla: adaptaciones y pervivencias tras la Guerra de las Alpujarras (1570-1610). También forma parte de los trabajos realizados en el seno del P. I. La Monarquía Hispánica y las minorías: agentes, estrategias y espacios de negociación (Ref.: HAR2015-70147-R) del MINECO. El autor quiere agradecer al profesor B. Franco Llopis (UNED) la lectura previa del original, así como sus consejos, orientaciones y sugerencias.

** Universidad de Castilla-La Mancha.

1. Para ver el origen, evolución y estado de la cuestión de esta línea de trabajo véase G. A. FRANCO RUBIO, «La historia de la vida cotidiana en la historiografía modernista española. Algunas reflexiones», en G. A. Franco Rubio (ed.), La vida de cada dia. Rituales, costumbres y rutinas cotidianas en la España moderna, Madrid, Almudayna, 2012, pp. 17-65, así como, entre otros, los informes monográficos que han dedicado al tema las revistas Chronica Nova (2009) y Cuadernos de Historia Moderna en sus Anejos correspondientes a 2009 y 2015. 
El desembarco de los modernistas en estas lides se ha producido desde diferentes puntos de partida. Los hay que proceden de la historia cultural; otros de la historia de la Iglesia y la religiosidad, incluso de la historia política, dado que algunas contribuciones partieron del análisis de la sociedad cortesana. Existe, incluso, una componente relacionada con los estudios de género, pues hay análisis que se orientan a desentrañar los hábitos diarios de las mujeres, aspecto en el que, incluso, se comparte espacio con la historia de la familia y con la demografía. En todo caso, y a pesar de la vitalidad de estos enfoques, en muchas ocasiones nos situamos ante trabajos cuya génesis se vincula a la historia económica. En nuestro país, dicha corriente alcanzó su punto álgido durante los años noventa del siglo XX y, al contrario de lo que ocurrió con las anteriores, manifestó una mayor ligazón con la historiografía anglosajona.

En ese contexto, y por sorprendente que pueda parecer, la vida cotidiana de los moriscos constituye un tema casi inexplorado o cuando menos, aún por desarrollar. El despertar de la historiografía dedicada a la minoría tuvo lugar desde los años ochenta y partió de dos aproximaciones muy concretas: por un lado, los estudios inquisitoriales y por otro la historia regional. Desde entonces, el conocimiento que se posee acerca de dicho colectivo ha crecido hasta cotas difícilmente imaginables hace tan solo unos lustros. Comunicaciones a congresos y ponencias, monografías, artículos e incluso exposiciones han contextualizado en sus justos términos a la que fue una de las grandes minorías sociorreligiosas de nuestra Edad Moderna. La mayor parte de los trabajos sobre el colectivo han cubierto el estudio de lo económico y lo social; han analizado la vertiente religiosa, los procesos de asimilación y las relaciones con la Inquisición; han desentrañado su comportamiento demográfico y se han ocupado de conocer aspectos tan determinantes como la conflictividad, la fiscalidad o el idioma y las prácticas culturales. Frente a ello, y salvo referencias aisladas, la vida material de los moriscos no ha ejercido el mismo atractivo entre quienes nos dedicamos a este tema. Tampoco el IV centenario de la expulsión ha supuesto un verdadero revulsivo para este enfoque ${ }^{2}$.

Aun así, no faltan trabajos que invitan al optimismo ${ }^{3}$. La progresiva aparición de estas contribuciones no es algo aislado, sino que se enmarca en el de-

2. En torno al impacto historiográfico que ha dejado tras de sí la conmemoración del IV centenario de la expulsión véanse, entre otros, E. SORIA MESA y S. OTERO MONDÉJAR, «Una nueva encrucijada. La reciente historiografía sobre los moriscos», Tiempos Modernos. Revista electrónica de Historia Moderna, VII/21, 2010, pp. 1-13; M. BARRIOs AGUILERA, «Los moriscos en el IV Centenario de la Expulsión. Algunos libros», Cuadernos de Historia Moderna, 35, 2010, pp. 225235 y F. FERnÁNDEZ IZQUiERdo y F. J. MORENO DíAZ DEL CAMPO, «¿Qué nos ha dejado el IV centenario de la expulsión de los moriscos? Historiografía frente a bibliometría en el análisis de los dosieres monográficos publicados entre 2009 y 2011», Chronica Nova. Revista de Historia Moderna, 40, 2014, pp. 181-210.

3. Entre las aportaciones más recientes, cabe destacar, por la apuesta que suponen en el empleo de documentación notarial, los trabajos de Israel Lasmarías para Aragón, así como los de Manuel F. Fernández Chaves y Rafael M. Pérez García para Andalucía. Véase I. LASMARÍAs PONZ, 
sarrollo que han experimentado los estudios culturales en los últimos años en España. De hecho, entronca con la tradición historiográfica arriba descrita y une en un solo campo de trabajo la preocupación por el análisis de lo cotidiano con el interés que aún despierta el estudio de las minorías hispanas. Su objetivo es contribuir a definir a la minoría, observar cuáles fueron los rasgos principales que caracterizaron su comportamiento material y, en última instancia, ubicar al grupo en su entorno más cotidiano. El camino elegido parece claro y metodológicamente hablando prometedor porque parte de la suma de estudios de corte microanalítico que, mediante un ejercicio de comparación y contraste, persiguen establecer pautas generales, pero también diferencias y particularidades.

A pesar de todo, el trabajo que queda por hacer es mucho. La minoría de edad de esta particular línea de trabajo resulta muy visible a poco que se profundice en el estado en que se encuentran las publicaciones relativas al tema. Tanto es así que existe un palpable desequilibro entre lo que se conoce en relación a Granada y lo que, poco a poco, se va intuyendo que pudo ocurrir en el resto de territorios peninsulares. En cierto modo, ello ha dado lugar a la configuración de un esquema expositivo plagado de tópicos, en el que lo granadino es extrapolado a Castilla sin tener en cuenta las tremendas alteraciones que se produjeron tras la guerra de las Alpujarras. Muchas veces, incluso, se confunde y se hace un uso parcial e interesado de los binomios medieval/mudéjar por un lado y moderno/morisco por otro y se aplican categorías interpretativas propias de la etapa islámica a la Granada del XVI, contribuyendo a enmarañar aún más un panorama ya difícil de comprender en origen.

Los excesos -si es que se permite el empleo de dicho término- son especialmente visibles en lo relativo al análisis del vestuario, posiblemente la vertiente más manida de cuantas se han estudiado. Junto a ello hay otros asuntos, menos tratados. Uno de ellos es la casa, aspecto poco conocido en el interior de la península ibérica, más aún en los siglos XVI y XVII y en el caso concreto de los protagonistas de este trabajo. No en balde constituye uno de los temas en el que las generalizaciones se hacen tanto más evidentes, sobre todo en relación a la situación observada en la Granada de la primera mitad del Quinientos. Es por ello, por lo que las líneas que siguen pretenden aproximarse a ese escenario. Para ello, tomarán como referencia el ámbito territorial de Castilla la Nueva, el marco cronológico definido por la llegada de los expulsados tras la guerra de 1568-1570 y el caso concreto del propio espacio doméstico, aspecto en el que creemos que puede localizarse una visión concreta de los procesos de adaptación/ resistencia que los granadinos pusieron en marcha tras su exilio de Granada.

«Cultura material de los moriscos aragoneses: vestido y apariencia», en M. ${ }^{a}$ J. Casaus Ballester (coord.), Los moriscos en los señoríos aragoneses. Actas de las III Jornadas del Proyecto Archivo Ducal de Hijar. Archivo Abierto, Teruel, Centro de Estudios Mudéjares, 2013, pp. 211-244 y M. F. Fernández Chaves y R. M. Pérez García, «Las dotes de las moriscas granadinas y sevillanas. Cambios y adaptaciones de una cultura materia», en M. M. Lobo de Araujo y A. Esteves (coords.), Tomar estado: dotes e casamentos (séculos XVI-XIX), Braga, Centro de Investigaçao Transdisciplinar 'Cultura, Espaço e Memória', 2010, pp. 121-145. 


\section{LA CASA MORISCA DE GRANADA. LA CASA CASTELLANA DE LOS MORISCOS}

\section{Mi casa y mi hogar, cien doblas val ${ }^{4}$}

La casa constituye el espacio privado por excelencia. Como tal es apreciada no sólo por su mayor o menor valor económico, sino por ofrecer un marco en el que el individuo puede comportarse como es, al margen de los convencionalismos sociales.

Esa constatación, en la que pocas veces se repara, resulta más evidente aún en el caso de aquellos grupos que afrontaron una cotidianeidad limitada, coartada por la imposición de una legislación ad hoc y mediatizada por una vigilancia ejercida de manera constante y desde todas las esferas posibles, no solo las gubernativas. En esos casos concretos, el hogar se convierte en un espacio de socialización informal ${ }^{5}$ en el que el marginado, el minoritario, el no integrado -aquí el morisco- pone en marcha una extensa batería de actividades a través de las cuales persigue desarrollarse como persona y como miembro de una colectividad. Así visto, cabe entender la vivienda morisca como un lugar con una función que trasciende a la mera de habitación, dado que el propio individuo encuentra en ese espacio (en principio privado) el ágora donde relacionarse con los suyos.

Lamentablemente, no hay fuente que, por sí misma, describa esa función "añadida", de tal manera que para acercarse a ella el historiador se ve obligado a recurrir a testimonios indirectos. Si hubiera que señalar un tipo documental especialmente aparejado para estos menesteres, ese sería el proceso judicial, bien en su vertiente inquisitorial, bien en sus facetas civil y criminal ${ }^{6}$. Gracias a los testimonios de encausados y testigos puede observarse un escenario en el que la vivienda de los moriscos también se presenta como lugar de reunión social. Se trata de una faceta especialmente visible en aquellos pleitos en los que, independientemente del hecho juzgado, se incluyen informaciones acerca de los vínculos interpersonales en el núcleo familiar o que conciernen a la celebración de fiestas y reuniones de naturaleza diversa. También, y cómo no, en relación a la oración. No en vano, el hogar fue el único espacio en el que el morisco criptoislámico pudo practicar libremente su fe, incluso desarrollar un ejer-

4. S. De Covarrubias Horozco, Tesoro de la lengua castellana o española (I. Arellano y R. Zafras eds., Madrid, Iberoamerica, 2006).

5. Nos hemos ocupado de este asunto con detalles relativos a la Castilla posterior a las Alpujarras en F. J. MORENO DÍAZ DEL CAMPO, «El espacio doméstico como marco de sociabilidad en contextos de marginación. Hogar y realidad material de los moriscos de Castilla en el tránsito del siglo XVI al XVII», en Congresso Internacional SocyHume, 2016. Da Sociabilidade ao Património Histórico e Cultural. Évora 22-24.09.2016, Évora, CIDEHUS-UE, (en prensa).

6. La fuente es interesada y parcial, pero convenientemente analizada constituye un instrumento muy valioso. Véase al respecto el ya clásico, pero igualmente sugerente trabajo de C. GINZBURG, «Checking the Evidence: The Judge and the Historian», Critical Inquiry, 18/1, 1991, pp. 79-92. 
cicio de catequesis y proselitismo religioso, aunque ello le expusiera a potenciales miradas delatoras. De ahí la importancia de este tipo de informaciones, por aisladas que puedan parecer.

Las autoridades (primero en Granada y más tarde en Castilla) no fueron ajenas a esta situación. Tanto fue así que "a lo largo del siglo XVI diversas órdenes reales obligaron a los moriscos a mantener abiertas las puertas, con la intención de evitar la preservación de su religión y costumbres en la intimidad del hogar" ${ }^{\prime 7}$. En realidad, se trató de una limitación que hasta podría considerarse anecdótica, ya que parece que solo se aplicó en Granada y apenas estuvo limitada a los viernes y a los días en que la propia casa era centro de celebraciones colectivas. Su puesta en marcha fue prevista por la Junta de la Capilla Real de Granada y, como el resto de su articulado, recuperada por Felipe II a partir de 1566. Comparada con las restantes disposiciones de ambas normativas puede verse como algo menor puesto que, aparentemente, no obligaba a grandes sacrificios de tipo cultural. No obstante, y bien mirada, su aplicación era tan denigrante o más, puesto que implicaba una manifiesta pérdida de intimidad y, por ende, atacaba los cimientos del comportamiento y libertad individuales a que todos los moriscos aspiraban. Por ello fue objeto de quejas ${ }^{8}$. Entre quienes se opusieron a su puesta en marcha se encontraba Francisco Núñez Muley. Su testimonio, por conocido, no deja de ser interesante. De hecho, intenta minimizar esa sensación ya apuntada de que la privacidad del hogar pudo constituir el pilar sobre el que se sustentó la práctica criptoislámica de muchos de los suyos:

“En el quarto capítulo, en lo de las puertas auiertas viernes y domingos y fiestas, que sobre ello la premática habla que an de estar auiertas: es en muncho e gran perjuicio ansí de la república como a los naturales, que son gente de poco trato y conversación; y por falta de criados, y por los ladrones, y como tienen sus haciendas e cosechas sin puertas ni cerraduras, no se pueden tener todo lo que tienen en sus casas ençerrado, pues quedando las puertas auiertas y las dichas casas sin çerraduras, viene muy gran daño y suelta y libertad que se da a los ladrones y personas de poca conçiençia. Por[que] çerrar las puertas no es para ofender a la santa fee católica, ni se puede presumir en qué ni por qué; que si en caso diremos que alguno o alguna tenga pensamiento de usar de la seta, no se puede hazer en ninguna manera; y si tales viniesen de noche lo hizieran, porque la seta de los moros rrequiere soledad, como lo tengo dicho, y no juntas como los confesos" ${ }^{\prime \prime}$.

En todo caso, y a pesar de ello, el hogar, su función y disposición fueron cuestiones poco reguladas, sobre todo en comparación con otros asuntos como

7. A. ORIHUELA UZAL, «La casa morisca granadina, último refugio de la cultura andalusí», en VIII Simposio Internacional de Mudejarismo. De mudéjares a moriscos: una conversión forzada. Teruel 1517 de septiembre de 1999. Vol. II, Teruel, Centro de Estudios Mudéjares (Instituto de Estudios Turolenses), 2002, p. 753.

8. Ibidem.

9. Recogido en K. GARRAD, «The original 'Memorial' of don Francisco Núñez Muley», Atlante, 2, 1954, p. 216. Nótese la oposición que el propio Muley hace con los judeoconversos. 
los ya mencionados relativos al idioma, la indumentaria o las manifestaciones lúdicas y festivas. Quizás por ello, y también porque este aspecto resultaba de más difícil control, "el proceso de aculturación forzosa que sufrieron los moriscos granadinos desde los inicios del siglo XVI tuvo menos influencia en la arquitectura doméstica que en otros aspectos de su cultura material y costumbres" ${ }^{10}$.

El modelo de vivienda morisca granadina es bastante conocido. En las últimas tres décadas se han producido considerables avances, los cuales han sido posibles gracias al trabajo conjunto de arqueólogos, arquitectos e historiadores del arte. No obstante, es un asunto repleto de matices. El primero de ellos relativo al hecho de que la inmensa mayoría de las casas que se conocen se ubicaron en el medio urbano. Tampoco conviene olvidar que muchas de las conservadas (y gran parte de las mejor descritas) pertenecían a individuos encuadrados en los estratos más favorecidos de la sociedad cristiano-nueva, lo cual ha llevado a valorar caracteres solo pertenecientes a una parte del conjunto, precisamente aquella cuyo análisis puede resultar más vistoso ${ }^{11}$.

De entre las publicaciones que han analizado el tema destacan, por su seriedad, los trabajos de Orihuela $\mathrm{Uzal}^{12}$. Sus investigaciones abordan el conocimiento íntegro de dichas construcciones desde sus orígenes emirales y han permitido constatar que la casa morisca anterior a la guerra de las Alpujarras mantuvo las características básicas de la arquitectura nazarí tales como la existencia de pocas aperturas al exterior, el deseo implícito de privacidad o el empleo de tapias de mampostería, barro en los suelos y madera en las estructuras horizontales ${ }^{13}$. Tan solo se detectan leves modificaciones, más bien adaptaciones, que fueron resultado tanto de factores externos como de la evolución social y demográfica del antiguo reino nazarí tras la conquista. Entre estas últi-

10. A. Orihuela UZAL, «La casa morisca granadina, último...», p. 754. En el mismo sentido véase J. Caro Baroja, Los moriscos del Reino de Granada. Ensayo de historia social, Madrid, Istmo, 2000 (5 ed.), p. 140.

11. Véanse al respecto las descripciones contenidas en A. Almagro y A. Orihuela UzaL, «De la casa andalusí a la casa morisca: la evolución de un tipo arquitectónico», en J. Passini (coord.), La ciudad medieval: de la casa al tejido urbano, Cuenca, Ediciones de la Universidad de CastillaLa Mancha, 2001, pp. 51-70.

12. A. Orihuela Uzal, «La casa andalusí: un recorrido a través de su evolución», Artigrama, 22, 2007, pp. 299-335. Para soluciones prácticas y materiales empleados véase, del mismo autor, «Técnicas constructivas en la arquitectura doméstica de los moriscos granadinos», en A. de las Casas, S. Huerta, E. Rabasa e I. Madrid (eds.), Actas del I Congreso Nacional de Historia de la Construcción. Madrid, 19-21 septiembre 1996, Madrid, Instituto Juan de Herrera (CEHOPU), 1996, pp. 395-398. A las aportaciones ya citadas, cabe añadir M. ${ }^{a}$ E. DíEz JoRGE, "Casas en la Alhambra después de la conquista cristiana (1492-1516): pervivencias medievales y cambios», en M. ${ }^{a}$ E. Díez Jorge y J. Navarro Palazón (eds.), La casa medieval en la Península Ibérica, Madrid, Sílex, 2015, pp. 395-463. En el mismo volumen, y más circunscrito al espacio rural (tan pobremente tratado en términos generales), véase el texto de M. ${ }^{a}$ A. FAJARDO MOLINA, «Habitando la alquería. Aproximación a la vivienda rural granadina tras la conquista de 1492», en M. ${ }^{a}$ E. Díez Jorge y J. Navarro Palazón (eds.), op. cit., pp. 487-517.

13. A. Orihuela UzAL, «La casa andalusí...», pp. 325-327. 
mas habría que señalar las relativas a la utilización del espacio, debidas a la intensificación del poblamiento que había experimentado Granada desde finales del $\mathrm{XIV}^{14}$ y que dieron lugar al levantamiento de plantas altas y a la progresiva especialización funcional de las estancias. Junto a ello, y como resultado de una influencia exógena al propio emirato, cabría señalar también la paulatina introducción de pórticos peristilos en los patios -a la manera castellana-, en respuesta a la necesidad de dotar de vías de circulación externas a las propias habitaciones. Finalmente, no es menos importante en esta etapa la incorporación de materiales y técnicas constructivas procedentes de la Castilla meridional tales como la fábrica mixta de ladrillo y mampostería o el empleo de decoraciones góticas y renacentistas en la carpintería ${ }^{15}$.

Todos estos aspectos permitirían hablar de un modelo autóctono, pero progresivamente castellanizado, incluso antes del abrupto corte que supuso el levantamiento de diciembre de $1568^{16}$. En todo caso, la auténtica transformación a la que tuvieron que hacer frente los granadinos fue la que se derivó de su destierro. Al contrario de lo que ocurrió en Granada, en Castilla, los cambios sí alcanzaron al hogar y a su configuración. Cabe recordar que en la pragmática de 1572 se insistió con vehemencia en dispersar a los expulsados. Ese asunto, perfectamente conocido ${ }^{17}$, debía aplicarse también en la esfera local, facilitando su establecimiento y tratando de impedir la creación de guetos. Sin embargo, el contenido de la pragmática no fue más allá. Nada se estipuló acerca de las condiciones en que debían residir los desterrados ${ }^{18}$ y ni mucho menos se establecieron limitaciones, vetos o indicaciones de ningún tipo. Ni tan siquiera en relación a las órdenes que motivaron las quejas ya vistas de Núñez Muley.

En realidad, tal posicionamiento no tuvo nada de extraño. Primero, porque la propia pragmática (como todos los textos normativos de la época) hizo suyos aquellos aspectos de la de 1567 que no estaban incluidos específicamente en su articulado. También, y sobre todo, porque la vigilancia y el control operados con los desterrados cambiaron a partir de su instalación en Castilla y se hicieron más intensos al imponer (y desarrollar) los criterios de auto-censura y de vigilancia recíproca, entendidos como parte de un proceso en el que los propios moriscos se convirtieron en vigilantes y vigilados.

14. A. Almagro y A. Orihuela Uzal, op. cit., p. 52.

15. A. Orihuela Uzal, «The Andalusi House in Granada (Thirteenth to Sixteenth Centuries)», en G.D. Anderson y M. Rosser-Owen (eds.), Revisiting Al-Andalus. Perspectives on the Material Culture of Islamic Iberia and Beyond, Leiden-Boston, Brill, 2007, pp. 180-181.

16. En gran parte, y como se encargan de señalar Almagro y el propio Orihuela, debido a la permanencia en el reino con posterioridad a 1570 de maestros albañiles y carpinteros moriscos. Véase A. Almagro y A. Orihuela Uzal, op. cit., pp. 67-69.

17. B. VinCENT, «L'expulsion des Morisques du Royaume de Grenade et leur répartition en Castille (1570-1571)», Mélanges de la Casa de Velázquez, 6, 1970, pp. 211-246.

18. Salvo las iniciales recomendaciones de que, en el transcurso de la instalación en los núcleos de destino, quedaran al cargo y bajo la supervisión y protección directa de cristianos viejos de reputada y solvente trayectoria. 
En tales condiciones, los recién llegados tuvieron que hacer frente a su instalación en viviendas que, desde el punto de vista de su distribución y de su concepción organizativa, representaron un modelo diferente al nazarí/ morisco ${ }^{19}$. En ese sentido y para comprender las implicaciones que dicha transformación acarreó en el comportamiento material de los granadinos, cobran especial relevancia las palabras que hace años dejara escritas Josep Ivars al afirmar que:

"El modelo arquitectónico, con sus variantes, es un elemento idóneo para resumir los caracteres de una civilización, ya que con él se expresa un modo de vida y unas costumbres. Si pueden existir dudas cuando analizamos un sistema constructivo, que si bien nos señala el origen de sus constructores no nos dice quién lo usa o habita, en cambio con un modelo arquitectónico todo es más evidente: nadie habitará en un modelo que no sea el de su propia civilización, y si en caso extremo, como el nuestro, se pasa violentamente de una propiedad musulmana a otra cristiana, ésta introducirá suficientes cambios como para desvirtuar el modelo o acoplarlo a sus necesidades" ${ }^{20}$.

Su reflexión parte del ejemplo opuesto al que aquí se analiza y constata los importantes cambios que la arqueología permitió observar en casas moriscas abandonadas tras la expulsión de 1609 y ocupadas más tarde por cristianos, pero parémonos un momento en sus palabras e invirtamos los términos. Preguntémonos si, tras su llegada a Castilla, los granadinos-obligados a vivir en ese "modelo" que no es propio de su civilización- no jugaron la doble baza de aceptar formalmente la solución de habitar un espacio castellano pero modificándolo en su interior para islamizarlo. Por fuerza, esa decisión implicó la utilización de objetos que, sin apartarse de lo legalmente permitido, pudieran ser utilizados "a la mora", constituyendo así un innegable nexo con la cotidianei-

19. Como acertadamente apunta la profesora Díez Jorge, "el espacio interior de la casa variaba enormemente según la clase social de sus ocupantes", desde una mayor flexibilidad en las viviendas de los más humildes a configuraciones más complejas y rígidas en el caso de aquellas que pertenecieron a familias más acomodadas. Aunque aún es mucho lo que queda por saber, parece existir cierto consenso a la hora de admitir que las casas de herencia nazarí presentan estancias y espacios (zaguanes, callejones y adarves, mayor importancia del patio, palacios...) y dimensiones (generalmente más reducidas) que permiten individualizarlas de las plenamente cristianas, representadas por el modelo castellano/cristiano al que, precisamente, se avanza en la Granada del XVI. En torno a estas cuestiones y, para el antiguo reino nazarí tras

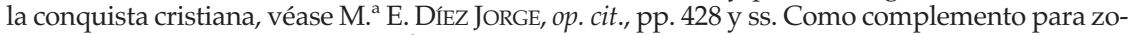
nas rurales granadinas, y como se ha indicado más arriba, véase M. ${ }^{a}$ A. MOLINA FAJARDO, op. cit., pp. 406-509. Para Castilla, véase F. J. Moreno DíAz DEL CAMPO, Los moriscos de La Mancha. Sociedad, economía y modos de vida de una minoría en la Castilla moderna, Madrid, Consejo Superior de Investigaciones Científicas, 2009, pp. 171-174. Para detalles en torno a la casa popular manchega a finales del XVI y principios del XVII véanse J. LÓPEZ GÓMEZ y A. LÓPEZ GÓMEZ, «La vivienda rural toledana en el siglo XVI según las 'Relaciones Topográficas'», Boletín de la Real Academia de la Historia, 189 / 1, 1992, pp. 1-21 y F. GARCíA GONZÁLEZ, «La casa rural en la Castilla meridional. Aproximaciones arquitectónicas y constructivas en la época del Quijote», en P. Sanz Camañes (coord.), La Monarquía Hispánica en tiempos del Quijote, Madrid, Sílex, 2005, pp. 103-144.

20. J. Ivars Pérez, «Unas viviendas moriscas en la Cairola (La Vall d'Ebo)», Sharq al-Andalus, 1, 1984, pp. 94-95. 
dad previa al destierro. En el contexto definido por esa situación es donde cobran especial relevancia los interiores, allí donde solo las fuentes escritas están en condiciones de ofrecernos un retrato aproximado de cómo se articuló la realidad material de los hogares de los moriscos granadinos afincados en Castilla en el tránsito del siglo XVI al XVII.

\section{LOS OBJETOS DE LA VIDA. REALIDAD PATRIMONIAL Y MATERIAL DE LOS MORISCOS DE CASTILLA. UNA VISIÓN DE CONJUNTO}

Durante el Antiguo Régimen, la configuración de los interiores domésticos y la creación de un marco espacial propiamente familiar tuvo un punto de inflexión claro: la boda. Entre las múltiples implicaciones sociales y económicas que se derivaban del pacto nupcial se contaba la creación y establecimiento del patrimonio de la pareja, que en la mayoría de las ocasiones tuvo en el otorgamiento de la dote una referencia inexcusable. No en vano, la firma de los contratos nupciales (y el conjunto de actos legales que los acompañaban) constituyeron un momento clave en procesos como la conformación de haciendas, la fijación de alianzas, la perpetuación de oficios y dedicaciones laborales o el reconocimiento implícito del papel de la mujer (y de su familia) en la conformación económica e instrumental de la casa ${ }^{21}$.

En el plano material su existencia no es menos importante porque constituye el soporte sobre el que, en gran medida, se asienta el hogar ${ }^{22}$. Así, el contenido de las cartas dotales no solo incluye transferencias de bienes raíces y pa-

21. Para una aproximación general desde el punto de vista estrictamente jurídico son de utilidad P. CEPEDA GÓMEZ, «La situación jurídica de la mujer en España durante el Antiguo Régimen y Régimen Liberal» y C. M. ${ }^{a}$ CREMADES GRIÑÁN y P. SÁnCHEZ PARRA, «Los bienes de las mujeres aportados al matrimonio. Estudio de la evolución de la dote moderna», ambos en M. GarcíaNieto Aparicio (ed.), Ordenamiento jurídico y realidad social de las mujeres. Siglos XVI a XX. Actas de las IV Jornadas de investigación interdisciplinaria, Madrid, Ediciones de la Universidad Autónoma de Madrid, 1986, pp. 181-193 y 137-147, respectivamente. En relación a los moriscos resulta muy apropiado recurrir a los trabajos de la profesora Birriel Salcedo, especialmente a M. M. ${ }^{\mathrm{a}}$ BIRRIEL SALCEDO, «Entre una ley y otra: la transmisión del patrimonio entre los moriscos granadinos», en M. C. Barbazza y C. Heusch (eds.), Familles, Pouvoirs, Solidarités. Domaine méditerranéen et hispano-américain ( $X V^{e}-X X^{e}$ siècles), Montpellier, Université de Montpellier III, 2002, pp. 227-236.

22. La bibliografía existente en relación a este asunto es abrumadora y sobrepasa los límites de este trabajo. Circunscritas al campo de la historia y al ámbito castellano, y en lo referido a los siglos XVI y XVII, pueden destacarse los trabajos del profesor M. GARCíA FERNÁNDEZ, «Familia y cultura material en Valladolid a mediados del siglo XVI. Entre el matrimonio y la muerte», en J. L. Castellano Castellano y F. Sánchez-Montes González (coords.), Congreso Internacional Carlos V. Europeísmo y universalidad. Granada, mayo de 2000 (vol. IV), Madrid, Sociedad Estatal para la Conmemoración de los Centenarios de Felipe II y Carlos V, 2001, pp. 275-296; «Las dotaciones matrimoniales en Castilla, siglos XVII-XIX. Mujer, alianzas económicas y cultura material», en M. C. Barbazza y C. Heusch (eds.), op. cit., pp.185-201; «La cultura material doméstica en la Cas- 
trimoniales o de capital dinerario. Tan importantes o más como esos aspectos resultan aquellos relativos al utillaje laboral o al ajuar. Y es en ese campo donde las escrituras nupciales constituyen un instrumento de primer orden a la hora de aproximarse a la configuración de la vivienda de moriscos y cristianos viejos durante la etapa posterior a la guerra de las Alpujarras.

Las posibilidades que ofrece la fuente son tremendas y pueden dar lugar al análisis de múltiples realidades (vestuario y moda, mundo del trabajo, sostenimiento económico de la familia...), pero las líneas que siguen se limitarán a lo estrictamente doméstico. Se trata de una elección puramente metodológica, que en modo alguno pretende minimizar la importancia del resto de categorías que pudieran establecerse, pero que creemos necesario resaltar dada la escasa literatura relativa a este tema concreto.

Para ello, se ha optado por analizar el comportamiento de las comunidades moriscas de Alcaraz, Almagro y Ciudad Real, tres de las localidades manchegas que tuvieron más relevancia económica durante la primera Edad Moderna. Su población conjunta superaba los veinticinco mil habitantes en el tramo final del siglo $\mathrm{XVI}^{23}$ y en un contexto económico dominado por la abrumadora presencia del sector agrícola, se alzaron como enclaves con una economía más diversificada ${ }^{24}$. A ello cabe unir el papel que ejercieron como enclaves político-administrativos, al ser cabeceras de sus respectivas demarcaciones, algo especialmente relevante en el caso de Almagro, situada al frente de la pujante gobernación del Campo de Calatrava.

Para ahondar más aún en el argumento, cabe señalar que, además, fueron tres de los núcleos manchegos que más desterrados recibieron tras la expulsión

tilla del Antiguo Régimen», en M. García Fernández y M. a Á. Sobaler Seco (coords.), Estudios en homenaje al profesor Teófanes Egido (II). Vol. V: Visiones literarias y literatura crítica, Valladolid, Junta de Castilla y León, 2004, pp. 249-270 y «La dote femenina: posibilidades de incremento del consumo al comienzo del ciclo familiar. Cultura material castellana comparada (1650-1850)», en I. dos Guimarães Sá y M. García Fernández (dirs.), Portas adentro. Comer, vestir, habitar (ss. XVI-XIX), Valladolid, Universidad de Valladolid-Universidade de Coimbra, 2010, pp. 117-148. Para Extremadura son muy útiles Á. RODRÍGUEZ SÁNCHEZ, «Las cartas de dote en Extremadura», en Actas del II Coloquio de Metodología Histórica Aplicada. La documentación notaria y la Historia. Vol. 2, Santiago de Compostela, Universidad de Santiago de Compostela, 1984, pp. 165-176 así como el modélico trabajo de F. ZARANDIETA ARENAS, «Riqueza y consumo en la Baja Extremadura en el siglo XVII. Análisis a través de las cartas de dote», Historia Agraria, 21, 2000, pp. $63-$ 97. Finalmente, en lo relativo a Castilla la Nueva debe recurrirse a C. HERNÁNDEZ LóPEZ, «Cultura material y especialización de la casa (Campo de Montiel, 1650-1850)», en J. M. Bartolomé Bartolomé y M. García Fernández (coords.), Apariencias contrastadas, contraste de apariencias: cultura material y consumos de Antiguo Régimen, León, Universidad de León, 2012, pp. 15-49 y «Pautas de consumo doméstico en las tierras de La Mancha oriental (1620-1850)», Ensayos. Revista de la Facultad de Educación de Albacete, 27, 2012, pp. 159-187.

23. J. LÓPEZ-SALAZAR PÉreZ, Estructuras agrarias y sociedad rural en La Mancha (ss. XVI-XVII), Ciudad Real, Instituto de Estudios Manchegos, 1986, pp. 669-670; F. J. MorENO, Los moriscos de La Mancha..., pp. 138 y 142-143

24. J. López-SAlazar Pérez, op. cit., pp. 21-33. 
de 1570-1571 25 . Particularmente significativa fue la situación de Ciudad Real durante los primeros años setenta, cuando el colectivo morisco llegó a representar una cuarta parte de su censo. Por su parte, Alcaraz y Almagro acogieron a contingentes más reducidos, aunque no menos significativos. De hecho, la villa calatrava se benefició de la llegada de granadinos que desde de la propia Ciudad Real consiguieron autorización para instalarse en pueblos vecinos en busca de mejores condiciones de vida. Algo parecido ocurrió en la localidad albaceteña, donde entre 1570 y 1610 los cristianos nuevos censados en ella se triplicaron, muy posiblemente como consecuencia de un movimiento migratorio opuesto al anterior (orientado en dirección campo-ciudad), pero motivado por iguales o semejantes motivos.

Tabla 1. Población morisca de las localidades analizadas

\begin{tabular}{lrrrrrrrrc}
\hline \multirow{2}{*}{ LOCALIDADES } & \multicolumn{2}{c}{1571} & \multicolumn{2}{c}{$1581-1586$} & \multicolumn{2}{c}{$1593-1596$} & \multicolumn{2}{c}{$1609-1610$} \\
\cline { 2 - 9 } & POB. & $\%^{*}$ & POB. & $\%^{*}$ & POB. & $\%^{*}$ & POB. & $\%^{*}$ \\
\hline Alcaraz & 180 & 2,1 & - & - & 214 & 2,8 & 565 & 6,4 \\
Almagro & 640 & 8,7 & 593 & 8,7 & - & - & - & - \\
Ciudad Real & 2684 & 24,7 & 1500 & 17,7 & - & - & 1580 & 18,4 \\
\hline
\end{tabular}

* Sobre la población total de cada localidad.

Fuente: F. J. Moreno, Los moriscos de La Mancha..., pp. 138 y 142-143.

El paso de los moriscos por los escribanos locales constituye un buen indicador de cómo se concretó su integración en la vida económica de Castilla. Gracias a los protocolos notariales puede afirmarse que el comportamiento económico de la minoría alcanzó ciertas cotas de normalidad a partir de la década de los años ochenta del Quinientos. Las escrituras que se han examinado para la redacción de este y otros trabajos relativos a minoría en tierras de La Mancha confirman esa apreciación e informan acerca del momento, las circunstancias y los sistemas que los granadinos emplearon para concretar sus ope-

25. Al menos de cuantos conservan documentación notarial en los archivos provinciales de Ciudad Real, Toledo y Albacete. También se ha consultado documentación relativa a las localidades toledanas de Ocaña, El Toboso y Quintanar de la Orden, pero sin resultados favorables dado que no ha podido extraerse dato alguno relativo a los granadinos. La muestra empleada ha partido del examen de 138 protocolos (30 pertenecientes a Alcaraz; 36 de Almagro y 72 correspondientes a Ciudad Real) fechados entre 1569 y 1610 y ha permitido documentar 95 familias diferentes en Alcaraz (11 moriscas); 173 en Almagro, de las cuales 16 tuvieron otorgantes moriscos y 586 en Ciudad Real (108 de cristianos nuevos). El volumen total de entradas correspondientes a objetos inventariados ha ascendido a 50779 (4813 en Alcaraz, 8790 en Almagro y 37176 en Ciudad Real). 
raciones económicas. También de quiénes les acompañaron en su desarrollo. En ese contexto, los contratos nupciales resultan una fuente idónea para aproximarse al proceso de reconstrucción material del hogar, a las inquietudes trasladadas al mismo y a las aspiraciones que se derivaban de él.

El examen del valor de los inventarios constituye una primera vía de aproximación. Sin embargo, cabe advertir que es un acercamiento que puede despertar ciertas dudas, sobre todo en un trabajo de las características del presente. Ello es debido a las enormes distorsiones que se producen al analizar de manera conjunta bienes de una naturaleza tan diferente como pudieron ser, por ejemplo, una parcela de viñedo y una sábana. Tanto es así que su toma en consideración solo se contempla como un preámbulo al estudio de los objetos del hogar, donde, a nuestro juicio, lo importante no es tanto su valor como su mera presencia (y por ende su número y la frecuencia con la que aparecen).

Hecha esa advertencia, tampoco sobra admitir que su análisis resulta de utilidad a la hora de calibrar la magnitud económica de los artículos que conformaron cada una de las partidas que se han establecido. El primer aspecto que llama la atención es la enorme brecha que se constata en relación a la inversión que moriscos y cristianos viejos destinan a patrimonio. Su transmisión sirvió, en el caso de estos últimos, para armar un "bolsa" que, de media, siempre se situó por encima de los dos tercios del montante total de las haciendas familiares. Sin ninguna duda, es algo que está relacionado con las posibilidades económicas que tuvo cada grupo y que se hace más visible en las parejas que gozaron de una posición desahogada, sin que en esta ocasión medie influencia cultural de ningún tipo. Las distancias se redujeron desde inicios del siglo XVII. En cambio, la pujanza de los grandes patrimonios y las reducidas posibilidades económicas de que aún disponían los moriscos, así como los intereses particulares de cada grupo, polarizaron el esquema de distribución de riqueza y motivaron que los cambios apenas si fueran perceptibles. Asimismo, la vigencia del esquema descrito también ha permitido constatar que las disimilitudes persistieron durante todo el periodo estudiado; que los matices crecieron con el tamaño de cada localidad ${ }^{26}$ y que, al contrario de lo que pudiera suponerse en un principio, las distancias intra-grupales fueron más acusadas en el caso de los cristianos viejos que en los moriscos, colectivo que, a pesar de su discreta riqueza, se ha revelado como más compacto en términos generales.

Las tornas cambian cuando se analizan los ajuares. Primero, porque los cristianos nuevos dedicaron una parte importante de su inversión al atesoramiento de joyas, bienes suntuarios y pequeñas cantidades de metales preciosos, lo que elevó la valoración final de la categoría en la que se incluyeron los objetos de las personas. También -y aunque ello exceda los límites que nos hemos impuesto en este trabajo- porque privilegiaron la cesión de prendas de ves-

26. Las diferencias, siempre a favor de los cristianos viejos, superan el doble en Alcaraz $(\times 2,2)$ y el triple en Almagro mientras que en Ciudad Real son seis veces mayores $(\times 6,4)$. 
Gráfico 1. Patrimonio nupcial de moriscos y cristianos viejos en La Mancha (1570-1610)

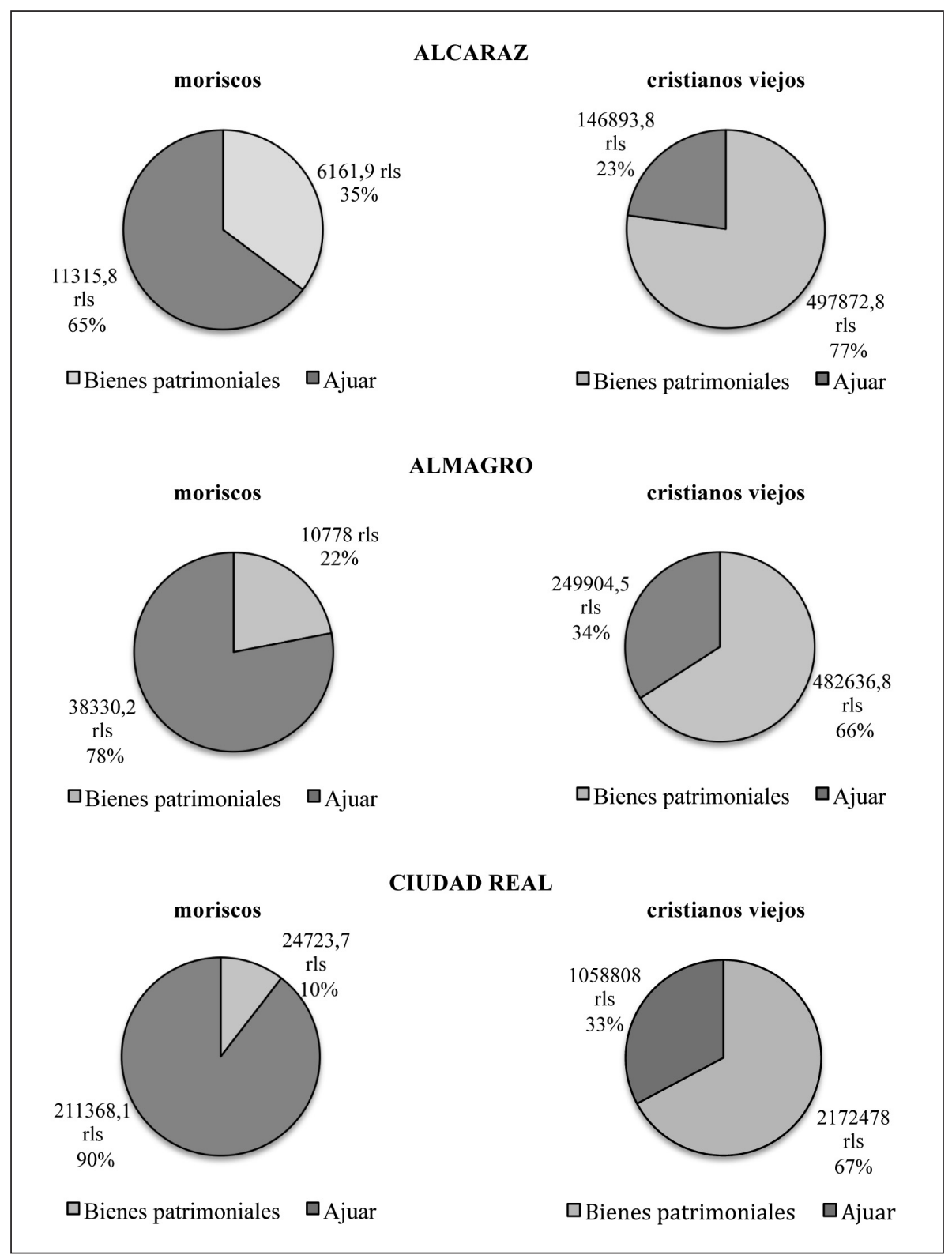

Fuente: Para Alcaraz, AHP Ab. Protocolos. Diversos legajos (1570-1610). Para Almagro y Ciudad Real, AHP CR. Protocolos. Diversos legajos (1570-1610). 
Tabla 2. Ajuares de moriscos y cristianos viejos en La Mancha (1570-1610)

\begin{tabular}{|c|c|c|c|c|c|c|}
\hline & \multicolumn{6}{|c|}{ VALORACIONES EN REALES } \\
\hline \multirow{3}{*}{$\begin{array}{l}\text { CATEGORÍA } \\
\text { DE OBJETOS }\end{array}$} & \multicolumn{2}{|c|}{ ALCARAZ } & \multicolumn{2}{|c|}{ ALMAGRO } & \multicolumn{2}{|c|}{ CIUDAD REAL } \\
\hline & MORISCOS & CRISTIANOS & MORISCOS & CRISTIANOS & MORISCOS & CRISTIANOS \\
\hline & & VIEJOS & & VIEJOS & & VIEJOS \\
\hline $\begin{array}{l}\text { Bienes y objetos } \\
\text { de las personas }\end{array}$ & 7546,1 & 64055,2 & 20668,6 & 104344,1 & 128053,6 & 495025,1 \\
\hline Hogar & 3769,8 & 82838,6 & 17661,6 & 145560,3 & 83314,5 & 563783,0 \\
\hline \multirow[t]{2}{*}{ TOTAles } & 11315,8 & 146893,8 & 38330,2 & 249904,5 & 211368,1 & 1058808,2 \\
\hline & \multicolumn{6}{|c|}{ PORCENTAJE } \\
\hline \multirow{3}{*}{$\begin{array}{l}\text { CATEGORÍA } \\
\text { DE OBJETOS }\end{array}$} & \multicolumn{2}{|c|}{ ALCARAZ } & \multicolumn{2}{|c|}{ ALMAGRO } & \multicolumn{2}{|c|}{ CIUDAD REAL } \\
\hline & MORISCOS & CRISTIANOS & MORISCOS & CRISTIANOS & MORISCOS & CRISTIANOS \\
\hline & & VIEJOS & & VIEJOS & & VIEJOS \\
\hline $\begin{array}{l}\text { Bienes y objetos } \\
\text { de las personas }\end{array}$ & 66,7 & 43,6 & 53,9 & 41,8 & 60,6 & 46,8 \\
\hline Hogar & 33,3 & 56,4 & 46,1 & 58,2 & 39,4 & 53,2 \\
\hline TOTALES & 100 & 100 & 100 & 100 & 100 & 100 \\
\hline
\end{tabular}

Fuente: Para Alcaraz, AHP Ab. Protocolos. Diversos legajos (1570-1610). Para Almagro y Ciudad Real, AHP CR. Protocolos. Diversos legajos (1570-1610).

tir, sobre todo femeninas ${ }^{27}$. Por el contrario, se ha detectado que el morisco -sin duda debido a motivos económicos- presentó un comportamiento más pacato a la hora de transmitir géneros textiles, lo que, en cierto modo, equilibró las cifras finales. A pesar de ello, el esfuerzo dedicado por las familias de granadinos a la compra y posterior cesión de bienes personales es sensiblemente superior al de los cristianos viejos ${ }^{28}$.

Algo parecido, pero a la inversa, ocurrió en el hogar, donde los moriscos invirtieron menos que los cristianos viejos. No obstante, en esta ocasión, las diferencias se mitigan al situarse siempre por debajo del doble. En gran medida,

27. Sirva como ejemplo el caso concreto de Ciudad Real, donde la suma de los valores conjuntos relativos al vestuario masculino y femenino alcanza, en los moriscos, el 43,3\% de la tasación global de los patrimonios familiares, mientras que en el caso de los cristianos viejos apenas si alcanza el 10\% $(9,6)$.

28. En este caso, las diferencias, siempre a favor de los moriscos son ligeramente inferiores a las ya vistas en los bienes patrimoniales, pero algo más uniformes (Alcaraz: $\times 4,3$; Almagro: $\times 2,9$; Ciudad Real: $\times 3,5$ ). 
ello es debido a que lo inventariado en las dotes moriscas fue superior y alcanzó un valor más alto en todo lo relativo a la ropa doméstica mientras que los cristianos viejos prestaron más atención al menaje y al mobiliario (gráfico 1).

Gráfico 2. Valoración por localidades y grupos de los objetos domésticos* incluidos en los patrimonios nupciales de moriscos y cristianos viejos

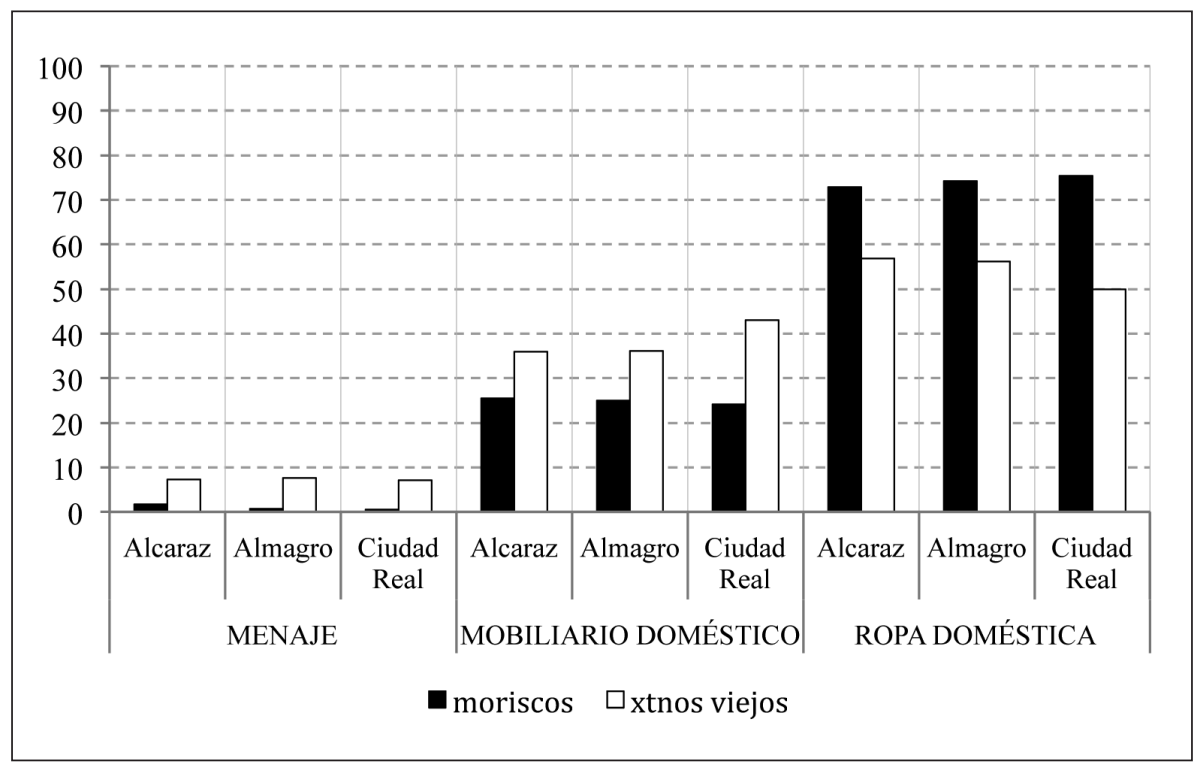

* Por categorías.

\section{MORISCOS Y CRISTIANOS VIEJOS EN EL HOGAR. SUSTRATO COMÚN, PAUTAS DIFERENCIADAS}

Confusión de espacios, escasa o nula jerarquización de las estancias, mezcla de funciones... fueron las principales características de la mayor parte de las viviendas populares en el medio rural y semi-urbano de Castilla la Nueva. Esas limitaciones se hacían tanto o más evidentes cuando el espacio doméstico era también el lugar de trabajo o cuando los hombres tenían que compartir espacio con animales de labor ${ }^{29}$. En ese contexto, y ante la falta de elementos arqui-

29. F. GARCía GONZÁLEZ, «La casa rural...», pp. 115 y 125. Véase en el mismo sentido y para Castilla la Vieja M. GARCÍA FERNÁNDEZ, «Estancias y mobiliario doméstico multifuncional: alcobas y camas», en G. A Franco Rubio (ed.), op. cit., pp. 144-145. Evidentemente no afectaron a 
tectónicos de entidad, fueron los cortinajes, esteras, alfombras... los que contribuyeron a definir la fisionomía de la casa. Debido a ello ropas blancas y de cama y mobiliario se convirtieron en elementos que definieron la usabilidad de los espacios y la concepción que del propio hogar tuvieron quienes lo habitaron, erigiéndose en un elemento cultural e identitario de primer orden ${ }^{30}$.

A la vista de los datos ya comentados, queda claro que, bajo ningún concepto, los artículos asociados al hogar fueron los más relevantes desde el punto de vista económico. Tal afirmación es válida para los cristianos viejos, de quienes ya se ha visto que, siempre que hubo posibilidades, optaron por las inversiones patrimoniales como vía prioritaria de erección de sus respectivas haciendas familiares. En el caso de los moriscos se detecta un comportamiento similar. Sin embargo, ante la imposibilidad de adquirir bienes raíces o ganado, de ahorrar y transmitir dinero en metálico o de contar con el respaldo financiero de juros y censos, los granadinos consagraron sus esfuerzos a la adquisición de joyas al tiempo que derivaron parte de su riqueza a la compra de vestuario y complementos personales.

El análisis de la distribución y frecuencia con la que aparecen los distintos enseres en los hogares de moriscos y cristianos viejos permite conocer la extensión en el uso de determinados productos y las preferencias mostradas por cada grupo ${ }^{31}$. Es cierto que presenta problemas de interpretación y que puede constituir un elemento de distorsión en el estudio de casos particulares, pero su empleo resulta complementario, incluso más adecuado cuando se intentan fijar comportamientos colectivos ${ }^{32}$. En este caso concreto ha permitido desvincular nuestra observación de lo estrictamente económico y fijar la base sobre la

todos los grupos sociales ni a todas las casas por igual, pero son numerosos los ejemplos en los que las estancias estrictamente habitacionales compartieron espacio con otras destinadas a fines laborales. Incluso fue frecuente que algunas transformaran su fisionomía y se adaptaran en determinados momentos del día al desempeño de actividades de corte profesional. Así le ocurrió, por ejemplo, a Diego de Baena, granadino alistado en Ciudad Real, quien en 1603 alquiló por espacio de cuatro años "una casa-tienda con sus cámaras y corredores", que tenía salida directa a la plaza pública de la ciudad y que, tras ser cerrada, se convertía en el hogar de su propia familia. AHP CR. Protocolos, leg. 77-1, ff. 192r-192v. 11.03.1603.

30. Aunque los vocablos empleados en las dotes analizadas aquí ya parecen ser plenamente castellanos, no sobra considerar la importancia que revistió el empleo de uno u otro término para referirse, en árabe, a realidades materiales y objetos domésticos similares, pero no siempre iguales ni igualmente utilizados. En torno a este aspecto, y a la riqueza terminológica andalusí en todo lo relativo al hogar, véase D. SERRANO NIZA, «Amueblar la casa con palabras. Fuen-

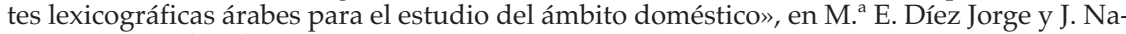
varro Palazón (eds.), op. cit., pp. 307-335.

31. En el caso de estudios con un marco temporal amplio, reviste una utilidad contrastada para acercarse a la evolución de los gustos y las modas que afectaron a la transmisión o adquisición de cualquier objeto.

32. En torno a los problemas y ventajas véase J. TORRAS, M. DURÁN y L. TORRA, «El ajuar de la novia. El consumo de tejidos en los contratos matrimoniales de una localidad catalana, 16001800», en J. Torras y B. Yun (dirs.), op. cit., pp. 65-66. 
que proceder a un examen cualitativo. Para ello se han establecido cuatro conjuntos de objetos en los que, a su vez, se incluyen agregados menores, relativos a la función y especificidad de los propios artículos inventariados (tabla 3).

Ciudad Real es la localidad donde el comportamiento de granadinos y cristianos viejos se presenta más dispar. Por su parte, las cifras de Alcaraz permiten intuir un mayor acercamiento entre ambos colectivos, incluso admitiendo que la disparidad sigue siendo una cuestión que conviene tener en cuenta. Ello invita a establecer una primera particularidad, que, obviamente, deberá afinarse a través de la toma en consideración de más estudios de caso, incluso no estrictamente relativos a la minoría morisca, sino a conjuntos poblaciones más amplios. No obstante, y dado que la muestra resulta sólida, cabe admitir que el espacio rural (representado aquí por Alcaraz y Almagro) hizo gala de una mayor homogeneidad que el ámbito urbano. De hecho, tanto los miembros de la elite local como los hacendados rurales de La Mancha de los siglos XVI y XVII, siempre se situaron "varios peldaños" por debajo de sus homólogos ciudarrealeños ${ }^{33}$ lo que, en último término, eleva las cifras de riqueza de los cristianos viejos y polariza el resultado final. A pesar de ello, las cifras obtenidas en los tres casos estudiados son coherentes y reflejan cierta lógica. Dicho de otro modo: no hay contradicción aparente entre ellas y denotan que moriscos y cristianos viejos se comportaron de manera diferenciada al tiempo que compartieron usos y costumbres con sus semejantes.

Sin duda, el dato que más llama la atención es la limitada presencia de útiles de menaje pertenecientes a moriscos. Obviamente, y en el estado actual de nuestros conocimientos, cualquier intento de explicación que pueda aportarse al respecto puede resultar arriesgado. De hecho, no sabemos si estamos ante una categoría poco apreciada o ante objetos incorporados al hogar por otras vías. Sea lo que sea, la casi absoluta insignificancia de estos utensilios está ahí y no parece que sea el resultado de uno de tantos caprichos estadísticos fruto del examen de la fuente aquí empleada. El ejemplo de Ciudad Real, vuelve a ser paradigmático, aunque, bien mirado, ni tan siquiera las cifras más altas (las de Alcaraz) permiten matizar en sentido opuesto la apreciación inicial ya señalada. Por su parte, las otras dos grandes categorías presentan un comportamiento homogéneo. A pesar de ello también se observa una tendencia clara, que permite constatar cómo el mobiliario es más numeroso (en términos absolutos, por supuesto, pero también proporcionales) en el caso de los cristianos viejos mientras que los granadinos privilegiaron la ropa del hogar.

33. J. López-Salazar Pérez y J. M. Carretero Zamora, "Ciudad Real en la Edad Moderna», en M. Espadas Burgos (coord.), Historia de Ciudad Real. Espacio y tiempo de un núcleo urbano, Ciudad Real, Caja de Castilla-La Mancha/ Ayuntamiento de Ciudad Real, 1993, p. 214. 
Tabla 3. Inventario de objetos presentes en los hogares de moriscos y cristianos viejos

\begin{tabular}{|c|c|c|c|c|c|c|}
\hline \multirow{3}{*}{$\begin{array}{l}\text { GRUPOS DE } \\
\text { ARTÍCULOS }\end{array}$} & \multicolumn{6}{|c|}{ VALORES ABSOLUTOS } \\
\hline & \multicolumn{2}{|c|}{ ALCARAZ } & \multicolumn{2}{|c|}{ ALMAGRO } & \multicolumn{2}{|c|}{ CIUDAD REAL } \\
\hline & MORISCOS & $\begin{array}{c}\text { CRISTIANOS } \\
\text { VIEJOS }\end{array}$ & MORISCOS & $\begin{array}{c}\text { CRISTIANOS } \\
\text { VIEJOS }\end{array}$ & MORISCOS & $\begin{array}{c}\text { CRISTIANOS } \\
\text { VIEJOS }\end{array}$ \\
\hline Menaje & 13 & 607 & 17 & 925 & 33 & 3728 \\
\hline MOBILIARIO DOMÉSTICO & 38 & 736 & 74 & 1482 & 415 & 6071 \\
\hline Almacenaje & 10 & 214 & 12 & 312 & 42 & 1413 \\
\hline Decoración & 2 & 96 & 23 & 261 & 208 & 1260 \\
\hline Muebles de dormitorio & 15 & 152 & 21 & 343 & 139 & 1226 \\
\hline Otros muebles & 11 & 274 & 18 & 566 & 25 & 2172 \\
\hline ROPA DOMÉSTICA & 105 & 1252 & 294 & 2474 & 1932 & 7634 \\
\hline Ropa blanca (aseo y mesa) & a) 19 & 302 & 36 & 568 & 322 & 1731 \\
\hline Ropa de cama & 70 & 729 & 187 & 1428 & 1040 & 4317 \\
\hline Otra ropa & 16 & 221 & 71 & 478 & 565 & 1586 \\
\hline ОтRоs & 0 & 14 & 4 & 23 & 7 & 198 \\
\hline \multirow[t]{2}{*}{ TOTALES } & 156 & 2609 & 389 & 4904 & 2387 & 17631 \\
\hline & \multicolumn{6}{|c|}{ PORCENTAJES } \\
\hline \multirow{2}{*}{$\begin{array}{l}\text { GRUPOS DE } \\
\text { ARTÍCULOS }\end{array}$} & \multicolumn{2}{|c|}{ ALCARAZ } & \multicolumn{2}{|c|}{ ALMAGRO } & \multicolumn{2}{|c|}{ CIUDAD REAL } \\
\hline & MORISCOS & $\begin{array}{c}\text { CRISTIANOS } \\
\text { VIEJOS }\end{array}$ & MORISCOS & $\begin{array}{l}\text { CRISTIANOS } \\
\text { VIEJOS }\end{array}$ & MORISCOS & $\begin{array}{c}\text { CRISTIANOS } \\
\text { VIEJOS }\end{array}$ \\
\hline Menaje & 8,3 & 23,3 & 4,4 & 18,9 & 1,4 & 21,1 \\
\hline MOBILIARIO DOMÉSTICO & 24,4 & 28,2 & 19,0 & 30,2 & 17,4 & 34,4 \\
\hline Almacenaje & 6,4 & 8,2 & 3,1 & 6,4 & 1,8 & 8,0 \\
\hline Decoración & 1,3 & 3,7 & 5,9 & 5,3 & 8,7 & 7,1 \\
\hline Muebles de dormitorio & 9,6 & 5,8 & 5,4 & 7,0 & 5,8 & 7,0 \\
\hline Otros muebles & 7,1 & 10,5 & 4,6 & 11,5 & 1,0 & 12,3 \\
\hline ROPA DOMÉSTICA & 67,3 & 48,0 & 75,6 & 50,4 & 80,9 & 43,3 \\
\hline Ropa blanca (aseo y mesa) & a) 12,2 & 11,6 & 9,3 & 11,6 & 13,5 & 9,8 \\
\hline Ropa de cama & 44,9 & 27,9 & 48,1 & 29,1 & 43,6 & 24,5 \\
\hline Otra ropa & 10,3 & 8,5 & 18,3 & 9,7 & 23,7 & 9,0 \\
\hline Otros & 0,0 & 0,5 & 1,0 & 0,5 & 0,3 & 1,1 \\
\hline TOTALES & 100 & 100 & 100 & 100 & 100 & 100 \\
\hline
\end{tabular}

Fuente: Para Alcaraz, AHP Ab. Protocolos. Diversos legajos (1570-1610). Para Almagro y Ciudad Real, AHP CR. Protocolos. Diversos legajos (1570-1610). 


\section{MenAJE}

El menaje constituye una categoría poco explorada. Su presencia en Europa occidental es vista como un símbolo de "civilidad" y de adopción de las prácticas burguesas propias de finales del XVIII y de la sociedad liberal. Cuando se habla de él, se piensa en el conjunto de utensilios que estaban presentes en la mesa a la hora de comer, pero los artículos que forman parte de esta categoría van mucho más allá e incluyen objetos relacionados con la cocina, con los trabajos domésticos y con el desenvolvimiento cotidiano.

En todo caso, son piezas que podrían incluirse entre aquellos enseres que el profesor Máximo García Fernández definía como de "necesidad básica" ${ }^{34}$ y de existencia casi gregaria y obligatoria en todos los hogares, lo cual pudo influir en muchos casos en el hecho de que ni tan siquiera fueran inventariados.

Tabla 4. Menaje presente en los hogares de moriscos y cristianos viejos en Ciudad Real, 1570-1610

\begin{tabular}{lcc|lcc}
\hline \multicolumn{3}{c|}{ CRISTIANOS VIEJOS } & \multicolumn{3}{c}{ MORISCOS } \\
\hline OBJETO & $\mathrm{N}^{\circ *}$ & $\%$ & OBJETO & $\mathrm{N}^{\text {o* }}$ & $\%$ \\
\hline Caldera & 455 & 12,2 & Caldera & 9 & 27,3 \\
Sartén & 446 & 11,9 & Sartén & 8 & 24,2 \\
Asador & 347 & 9,3 & Almirez & 7 & 21,2 \\
Artesa & 292 & 7,8 & Asador & 2 & 6,1 \\
Espetera & 276 & 7,4 & Artesa & 1 & 3,0 \\
Plato & 207 & 5,5 & Cacillo & 1 & 3,0 \\
Trébedes & 184 & 4,9 & Calderilla & 1 & 3,0 \\
Almirez & 144 & 3,8 & Calderillo & 1 & 3,0 \\
Cazo & 141 & 3,7 & Caldero & 1 & 3,0 \\
Canasta & 125 & 3,3 & Cazo & 1 & 3,0 \\
Cuchara & 93 & 2,5 & Trébedes & 1 & 3,0 \\
\hline
\end{tabular}

${ }^{1}$ Objetos más numerosos.

* Entradas de inventario.

La relación más completa de cuantas se han documentado es la relativa a Ciudad Real. En el caso de los cristianos viejos incluye casi un centenar de efectos diferentes que van desde los ya citados instrumentos de cocina y de chime-

34. M. GARCía FernÁNDEZ, «Los bienes dotales en la ciudad de Valladolid, 1700-1850. El ajuar doméstico y la evolución del consumo y la demanda», en J. Torras y B. Yun (dirs.), op. cit., p. 139 
nea (morillos, trasfuegos, tenazas...) hasta piezas de loza y vidrio y recipientes contenedores elaborados con materiales de diverso tipo (cestas, tabaques, escriños...). Por su parte, y en lo relativo a los moriscos, la lista es humilde, básica hasta extremo (tabla 4). Los utensilios más repetidos son las calderas (con 9 apariciones), la sartén (8), el almirez (7) y el asador (2) a los que sigue una escueta relación de objetos que únicamente aparecen una vez (artesa, cacillo, trébedes...). Como puede observarse, nada que se separe de lo habitual ${ }^{35}$.

No hay, pues nota definitoria que permita establecer separación alguna entre moriscos y cristianos viejos, exceptuando la consideración ya apuntada de que en el caso de los granadinos este tipo de utensilios mereció mucha menos atención $^{36}$. Muestra de ello es el propio ejemplo de Ciudad Real: de las 108 familias moriscas documentadas, solo $13(12 \%)$ incorporaron alguna pieza de menaje a sus casas ${ }^{37}$. En ellas, y frente a la relativa abundancia de artículos que poblaron las dotes de las cristianas viejas, solo se incluyeron unos pocos utensilios. No en balde, las descripciones más minuciosas solamente mencionan seis y cuatro útiles cada uno ${ }^{38}$. El resto es variable y presenta un número de objetos inferior, pero ha podido detectarse que en más de la mitad de los casos siempre se repite el binomio caldera/sartén. A ellos, y en un segundo plano, les suelen acompañar los almireces en lo que podría definirse como el conjunto de los "básicos" prácticamente irremplazables en todo hogar.

\section{MOBILIARIO DOMÉSTICO}

En cierto modo, los muebles constituyen un grupo que complementa y se completa recíprocamente con el menaje. Tanto es así que los datos de que disponemos muestran pautas similares a lo ya visto con los útiles de cocina, vidrios, lozas y demás utillaje. El análisis comparado del comportamiento de mo-

35. Asadores (3), calderas (2) y sartenes (2) también son los utensilios más comunes entre los moriscos de Alcaraz. Solo se invierte el orden. A ellos se añaden en el caso concreto de Almagro las limpiaderas y las cucharas, pero en cifras tan modestas que no permiten comentario alguno más allá del que sirve para constatar su nula importancia y menor consideración entre los moriscos.

36. Acaso nos situamos ante una muestra más del proceso de hibridación ya patente en otras zonas de Castilla desde los siglos plenomedievales, tal y como constató para el caso vallisoletano Olatz Villanueva a partir del estudio de la cerámica. Véase O. VILLANUEVA ZuBIZARRETA, Actividad alfarera en el Valladolid Bajomedieval, Valladolid, Universidad de Valladolid, 1998.

37. En el caso de los cristianos viejos fueron 449 de un total de $478(93,9 \%)$.

38. El primero es la dote de Ana López morisca casada en 1607 con Alonso de Nájera. Su dote, otorgada cuatro días antes de las velaciones, hace referencia explícita a un almirez, una sartén, un cazo, unas trébedes, un asador y una caldera (la partida de matrimonio en Archivo Parroquial de San Pedro. Ciudad Real. Libros sacramentales. Matrimonios, libro 1, f. 47v. 26.11.1607. La dote en AHP CR. Protocolos, leg. 58bis, ff. 375r-379r. 22.11.1607). El otro ejemplo que podría destacarse es el de Alonso de Baena e Isabel de Granada, quienes incluyeron en su dote una artesa, una caldera, una sartén y un almirez (AHP CR, Protocolos, leg. 110/1, ff. 150r-155v. 02.09.1607). 
riscos y cristianos viejos en relación a los muebles sugiere que, en este caso concreto, las distancias entre ambas comunidades se amortiguaron y que se hicieron menores con el paso del tiempo. Sin embargo, y en términos generales, tanto el esfuerzo destinado a la inversión como el volumen de los inventarios siguen siendo menores en el caso de los granadinos ${ }^{39}$.

$\mathrm{Al}$ igual que el menaje, el mobiliario presenta toda una serie de particularidades en las que conviene reparar. Como punto de partida las cifras globales invitan a considerar la existencia de unos patrones muy similares en ambas comunidades, pero, a poco que se profundiza en ellas, las diferencias se hacen visibles, llegando a constituir un rasgo distintivo en el caso de los muebles de dormitorio y en los de almacenaje. Por su parte, en lo relativo a decoración se detecta la existencia de cierto equilibrio, aunque hay que precisar la distinta naturaleza de los enseres preferidos por uno y otro grupo así, como, nuevamente, su número. No en vano, la gama de ornamentales que se incluyen en las dotes es mucho más monótona en el caso de los cristianos nuevos.

De nuevo volvemos a encontrar el listado más completo en Ciudad Real. A decir verdad, no resulta especialmente rico (27 entradas diferentes) y únicamente deja ver la presencia de artículos que podríamos considerar de la misma familia: paños y lienzos de pared, sábanas de colgar, paramentos... que, aparte su función estética, poseían un indudable sesgo práctico, dado que fueron empleados para mantener la confortabilidad de las estancias debido a sus propiedades aislantes ${ }^{40}$.

Como en el caso de los cristianos viejos, y a la espera de posteriores análisis, todo indica que el tejido más empleado por los moriscos fue el lienzo, solo o complementado con otros materiales ${ }^{41}$. La inmensa mayoría de estos elementos de pared carecían de adornos - $\mathrm{O}$ al menos nada se indica acerca del particular-, aunque tampoco resulta extraño que se diga de manera explícita que estaban pintados ${ }^{42}$. Esas descripciones no suelen ser muy detenidas, aunque sí permiten conocer que los motivos vegetales (de lampazos) fueron los más ha-

39. Solo se aparta -aunque tímidamente-Alcaraz, donde esa menor importancia sigue patente, pero con un comportamiento más equilibrado entre ambas comunidades.

40. Su uso se fue implantando poco a poco y sustituyendo a un elemento tan típicamente granadino como fue el guadamecí, tal y como observaron en su día Fernández Chaves y Pérez García en relación a la situación vigente en Granada antes de 1570 (FERNÁNDEZ CHAVES y R. M. Pérez GARCÍA, «Las dotes de las moriscas...», p. 138). Aun así se detecta un mayor uso por parte de los moriscos. En el caso de Ciudad Real, por ejemplo, alcanzó al 3,6\% del total de objetos inventariados en las dotes moriscas (15 de 416) mientras que en los cristianos viejos apenas si representa un $0,5 \%$ (32 de 6269)

41. Como por ejemplo el enrejado (tejido y tiras de red) o los encajes, cuya utilización no resultó extraña en los moriscos de Almagro. AHP CR. Protocolos, leg. 1830, s.f. 20.05.1607.

42. Tanto fue así que, en muchas ocasiones, el término "pintado" designa a un tipo concreto de paño de pared, posiblemente de uso común y muy accesible en los mercados locales a juzgar por la frecuencia con la que aparece en los inventarios analizados. 
bituales ${ }^{43}$. Menos frecuentes (posiblemente debido a su precio) fueron los bordados con seda ${ }^{44} \mathrm{y}$, sobre todo, los que reflejaron algunas escenas animales o representaciones humanas. En ese sentido resulta especialmente llamativa la presencia de un paramento de pared que perteneció a Gonzalo de Zafra e Isabel Núñez, moriscos de Ciudad Real, que estaba compuesto "con la historia del hijo pródigo" ${ }^{45} \mathrm{o}$ aquellos otros ilustrados también con narraciones y motivos hagiográficos como los relativos a las vidas de san Alejo y santa Casilda que hemos podido localizar en Ciudad Real ${ }^{46}$.

De hecho, y a pesar de ser habituales en los hogares de los cristianos viejos, este tipo de representaciones figurativas resultan bastante extrañas en las viviendas de los granadinos afincados en La Mancha. Aun así, y por anecdótica que resulte su aparición, su mera presencia ya es indicativa de un cambio con respecto a lo observado en Granada antes de la guerra de las Alpujarras, dado que allí no se han localizado ejemplos similares ${ }^{47}$. En último término, ello invitaría a considerar la posibilidad de que, aunque despacio y de una manera aún subrepticia, algo comenzaba a cambiar en los esquemas culturales y domésticos de los cristianos nuevos ${ }^{48}$. Téngase en cuenta que nos situamos ante ejemplos fechados en el tránsito de los siglos XVI al XVII, momento en el que una nueva generación de moriscos tomaba las riendas de sus respectivas comunidades. Es mucho lo que queda por saber al respecto, pero no sobra considerar la posibilidad de que ese cambio generacional, unido a la política de aculturación desplegada por la Corona y a la mejora de la situación económica de la minoría, estuviera en la base de un proceso de integración que ya empezaba a dar sus primeros frutos y que estos ejemplos no sean sino una muestra más de ello.

Más allá de la puntual importancia que pudieron representar los objetos "de pared", el mueble de decoración prácticamente brilló por su ausencia. Lo hizo en las viviendas de los moriscos, por supuesto, pero también en las de los cristiano-viejos. No en vano, y al menos por lo que conocemos hasta ahora, la aparición de mobiliario de este tipo y su mayor o menor frecuencia no implican connotación alguna de corte cultural, sino que más bien se vinculan a razones de orden económico. El problema es que, cuando aparecen -incluso cuando pertenecen a familias con un poder adquisitivo alto-, este tipo de efec-

43. AHP CR. Protocolos, leg. 31/9, ff. 5r-8r. 25.01.1590.

44. AHP CR. Protocolos, leg. 35bis/1, ff. 169r-172v. 22.03.1598.

45. AHP CR. Protocolos, leg. 75bis/2, ff. 354r-356v. 08.12.1600.

46. AHP CR. Protocolos, leg. 54, ff. 263r-267r. 07.10.1594 y AHP CR. Protocolos, leg. 78/1, ff. 326r329r. 31.12.1605. Para más detalle en torno a este aspecto véase B. FrANCO LLOPIS y F. J. MOREno Díaz del CAMPo, The Moriscos' (Artistic) Domestic Devotion(s) Viewed Through Christian Eyes in Early Modern Iberia, en prensa.

47. M. F. Fernández Chaves y R. M. Pérez García, «Las dotes de las moriscas...», p. 141.

48. F. J. MORENO DÍAZ DEL CAMPO, «El hogar morisco: familia, transmisión patrimonial y cauce de asimilación», Al-Kurras. Cuadernos de estudios mudéjares y moriscos, n 1/vol. I, 2015, p. 108. 
tos apenas si son descritos ${ }^{49} \mathrm{y}$ los datos que poseemos sobre ellos no permiten ir más allá de la mera especulación en lo relativo a su naturaleza, forma, disposición o función. En todo caso, y cuando sí se indica algo más, lo más frecuente es documentar tanto espejos como utensilios relacionados con la iluminación de la casa (hacheros, candeleros, candelabros, palmatorias.... $)^{50}$.

No hay, pues, excesivas diferencias. Solo puede señalarse como nota definitoria clara la presencia de esculturas y pinturas. Se trata, casi siempre, de elaboraciones menores, de las que cabe intuir que no destacaron por su excesiva calidad artística ${ }^{51}$, pero que debieron romper con la monotonía propia de aquellos espacios. En una inmensa mayoría de las ocasiones también representaron escenas de corte religioso, ya fueran vírgenes (normalmente bajo las advocaciones locales), ya crucifijos, eccehomos, Niños Jesús u otros miembros habituales en el santoral popular castellano de finales del XVI ${ }^{52}$. Algo similar ocurrió con los cuadros, en los cuales fue habitual la referencia a pasajes bíblicos e historias de santos como los ya vistos en el caso de los lienzos de pared. Cuando no fue así, las representaciones de temática profana incluyeron alegorías mitológicas y recuerdos históricos amén de otros temas que, por desgracia y debido a lo parco de las descripciones, no pueden ser identificados ${ }^{53}$. Su aparición en el caso de los cristianos viejos es habitual y afecta a todos los grupos sociales, independientemente de su nivel adquisitivo. De hecho, el único matiz que se advierte es el relativo a su composición, pues en los sectores más humildes abun-

49. Así ocurre, por ejemplo, con los "ornamentos" que doña Elvira Treviño guardaba en un cajón, de los que, por desgracia, poco conocemos, pues nada más se dice de ellos. Por el contrario, y a juzgar por su precio, no debieron ser ni escasos ni corrientes dado que su valoración ascendió a veinte ducados. AHP CR. Protocolos, leg. 71/3, ff. 5r-16v. 14.01.1601.

50. Por ejemplo, y entre otros, para el caso de Ciudad Real, en AHP CR, leg. 6, ff. 651r-660r. 07.01.1573; leg. 10, ff. 140r-147r. 13.08.1600 y leg. 47 / 1, ff. 205r-209v. 01.09.1607. En algunos casos este tipo de elementos también fueron utilizados desde un punto de vista religioso-cultual pues su presencia aparece ligada a la de pilas y pilillas, de las cuales se indica que eran "para agua bendita" (entre otros en AHP CR. Protocolos, leg. 1780/1, s.f. 01.01 .1600 y leg. 1828, s.f. 10.09.1606).

51. Debido a que, sobre todo, primaba su carácter y función devocional y no tanto la calidad de las piezas. En torno a este asunto resulta de obligada consulta del trabajo de A. URQUízAR HERRERA, Coleccionismo y nobleza: signos de distinción social en la Andalucía del Renacimiento, Madrid, Marcial Pons Historia, 2007.

52. El estudio de la religiosidad popular castellana en la época postridentina cuenta con dos notables aportaciones, basadas mayoritariamente en el empleo de las Relaciones Topográficas de Felipe II: W. A. Christian, Jr., Religiosidad local en la España de Felipe II, Madrid, Nerea, 1991 ( $1^{a}$ ed. en inglés, Princeton, Princeton University Press, 1976) y F. J. CAMPOS y FeRnÁNDEZ DE SEviLLa, La mentalidad en Castilla la Nueva en el siglo XVI. Religión, economía y sociedad según las 'Relaciones Topográficas' de Felipe II, San Lorenzo de El Escorial, Ediciones Escurialenses, 1986. Por desgracia, ambos trabajos no han gozado de mucho seguimiento posterior de tal manera que, en cierto modo, el tema puede completarse con el empleo de otras fuentes, entre ellas los protocolos notariales, aquí utilizados.

53. Por ejemplo, el cuadro de pintura "en tabla" con el que decoró su casa don Lorenzo Suárez de Figueroa y Cardona, regidor perpetuo de Ciudad Real, en el que se representaba la escena romana del suicidio de Lucrecia. AHP CR., leg. 56/1, ff. 100r-113r. 20.07.1597. 
daron las "estampas en papel" ${ }^{54}$, mientras que en los individuos y familias con una posición más desahogada no resultaron extraños los lienzos y las tablas con aderezos (marcos) ${ }^{55}$. No ocurre así en el caso de los moriscos pues sólo se ha documentado un ejemplo en el que el hogar se adorna con pinturas: el relativo a Beatriz de Mendoza y Miguel de Granada, quienes casaron en Almagro en 1606, y llevaron a su casa "cuatro imágenes en tabla", valoradas en apenas dieciséis reales $^{56}$. El silencio acerca de lo que representaban no deja de ser indicativo y permite deducir que no fueron, precisamente, motivos religiosos.

Finalmente, y para cerrar el apartado relativo a los muebles decorativos, cabe mencionar las alfombras, esteras y esterillas. Su consideración despierta cierta incertidumbre. No estamos ante un mueble propiamente dicho. Sin embargo, creemos que, a pesar de su carácter textil, tampoco pueden ser incluidas entre la ropa doméstica. Esas dudas resultan más evidentes en el caso de los moriscos, para quienes parece que gozaron de cierta aceptación. En realidad, su número no es muy alto, pero destacan por aparecer en posiciones relativamente elevadas en los listados de los propios granadinos ${ }^{57}$ mientras que para los cristianos viejos merecieron una consideración $\operatorname{menor}^{58}$; tanto que en la relación de objetos del hogar perteneciente a Almagro hay que descender hasta el vigesimosexto lugar para encontrarlas y al vigesimonoveno en Ciudad Real.

El resto del moblaje del hogar de La Mancha de finales del XVI tiene un protagonista claro: el binomio colchón-arca. Ambos aparecen en las dotes estudiadas (fuesen de moriscas o de cristianas viejas) y, juntos o por separado, constituyeron la base sobre la que se articuló el dormitorio, acaso la habitación que gozó de más personalidad, ya que en muchos casos estuvo independizada

54. En torno a este asunto véase J. VegA GOnZÁlez y J. PORTús Pérez, La estampa religiosa en la España del Antiguo Régimen, Madrid, Fundación Universitaria Española, 1998.

55. AHP CR. Protocolos, leg. 25/1, ff. 115r-124v. 25.02.1591.

56. AHP CR. Protocolos, leg. 1611, s.f. 04.05.1606.

57. Sirvan al respecto, entre otros, los ejemplos de Isabel de Escobar y Baltasar Porcel, quienes vistieron su hogar con un lote formado por seis o el de Bartolomé de Jaén, quien recibió de su esposa otras cinco. AHP CR. Protocolos, leg. 10, ff. 702r-705v. 23.06.1600 y leg. 79/1, ff. 331r333v. 15.03.1607, respectivamente.

58. Su relativa mayor presencia en Alcaraz puede deberse a una razón de orden estrictamente local, pues en la ciudad y su comarca se localizó durante toda la Edad Moderna una importante manufactura dedicada a estos objetos que, sin duda, debió ser aprovechada por los vecinos. A título de ejemplo puede mencionarse el caso de Florencia Méndez, cristiana vieja, que llevó en su dote tres alfombras valoradas en más de ochocientos reales. Solo una de ellas, "grande, de seis varas en largo y dos de ancho" fue tasada en cincuenta ducados. AHP Ab. Protocolos, leg. 1139/3, s.f. 02.06.1609. Véase al respecto A. PRETEl MARín, «Notas pintorescas sobre las alfombras de Alcaraz en los comienzos del siglo XVI», Al Basit, 0, 1975, pp. 6-11 y J. SÁNCHEZ FERRER, «Sobre las alfombras actuales de Lezuza y las antiguas de Alcaraz», Al-Basit, 9, 1981, pp. 117-138. Del mismo autor Alfombras antiguas de la provincia de Albacete, Albacete, Instituto de Estudios Albacetenses, 1981. 
de las demás, incluso en las viviendas más humildes ${ }^{59}$. Dentro de dicha estancia, el arca se convirtió en un referente ${ }^{60}$. Su uso se ligó a la guarda de los vestidos, especialmente (aunque no de manera exclusiva) de los de mayor porte y valor ${ }^{61}$. Junto a ellas también es frecuente que se cuenten cofres y baúles, posiblemente más ricos, pues solían incluir taraceados en algunas ocasiones ${ }^{62}$ y en la inmensa mayoría estaban encorados ${ }^{63}$.

No obstante, y tal y como se ha señalado más arriba, el elemento de mobiliario clave en todos los hogares fue el colchón. Su presencia es común a ambos grupos, pero en los inventarios moriscos ocupa un lugar prioritario. De hecho, es el objeto de mobiliario más frecuente tanto en las viviendas moriscas de $\mathrm{Al}$ magro como en las de Ciudad Real y el segundo (curiosamente solo por detrás de la cama) en Alcaraz, mientras que esos mismos enseres descienden algunos escalones en el caso de los cristianos viejos ${ }^{64}$. Aparte de ello, tampoco parecen darse excesivas diferencias ni en el número ${ }^{65}$, ni en los rellenos (de lana, borra o tascos), ni en los materiales (lienzo, lino y estopa), ni tan siquiera en los colores ${ }^{66}$.

59. De dicha estancia dice el profesor García Fernández que fue "centro receptor clave" de los enseres dotales. Véase M. GARCíA FERNÁNDEZ, «Estancias y mobiliario doméstico...», p. 149. En torno a la importancia del arca en otros ámbitos moriscos véase M. ${ }^{a}$ I. ÁlVARO ZAMORA, «Inventario de bienes moriscos de Villafeliche en 1609: su condición social, localización de las viviendas, tipología y distribución interior, y ajuar», Artigrama, 2, 1985, pp. 95-111.

60. Ya empezaba a serlo en la Granada de principios del XVI según indica M. ${ }^{a}$ E. DíEZ JorGE, op. cit., p. 450.

61. I. LASMARÍAS PONZ, «Cultura material de los moriscos aragoneses...», p. 235.

62. AHP Ab. Protocolos, leg. 1131/2, ff. 225r-227v. 18.04.1608.

63. Entre otros, y, por ejemplo, en AHP Ab, leg. 1133/2, ff. 230r-241r. 20.09.1590 y AHP CR. Protocolos, leg. 1611, s.f. 04.05.1606 y leg 45/1, ff. 325r-329v. 20.09.1606, estos dos últimos moriscos.

64. Hasta el tercer puesto en Ciudad Real y Almagro y al sexto en Alcaraz.

65. Lo normal fue incorporar uno, aunque no son raros los ejemplos en los que hubo dos. Solo se han documentado dos casos con seis: el de doña Cecilia Tenoria, de Alcaraz, a quien se los valoraron en la nada despreciable cifra 386 reales (AHP Ab. Protocolos, leg. 1119/1, ff. 312v-314v. 30.10.1600) y el de doña Francisca de Huelva (AHP CR. Protocolos, leg. 1611, s.f. 26.01.1606). Por su parte, Isabel Gutiérrez, morisca de Almagro, llevó cinco (AHP CR. Protocolos, leg. 1830, s.f. 20.05.1607). Aparte de ella, los moriscos que más incorporaron fueron Isabel de Guzmán y Francisco de Zafra, quienes llevaron a su casa cuatro de lienzo, "listados de azul" y poblados (dos con lana castellana y dos con borra) (AHP CR. Protocolos, leg. 36/2, ff. 183r-188v. 22.11.1602). Para época andalusí, Dolores Serrano indica en el trabajo lexicográfico ya citado, que las diferencias provenían de "las posibilidades que las personas tuviesen" y establece, a partir de los trabajos de J. Sadan una triple gradación. Véase D. SERRANO NizA, op. cit., p. 316.

66. Al contrario de lo que ocurre en las ropas domésticas y personales no abundan las menciones al color por lo que, a falta de indicaciones al respecto, debemos pensar que la inmensa mayoría fueron blancos, crudos a lo máximo. Como nota particular puede señalarse la presencia de algunos listados de azul y blanco (por ejemplo, en AHP CR. Protocolos, leg. 1779/1, s.f. 29.03.1598, para cristianos viejos y en AHP. Protocolos leg. 30bis/4, ff. 1r-4r. 03.11.1589 y 5r8r. 16.04.1589 para moriscos), colorados (AHP CR. Protocolos, leg. 1614, s.f. 17.10.1600) e, incluso amarillos (AHP Ab. Protocolos, leg. 1133/2, ff. 230r-241r. 20.09.1590 y leg. 1135, ff. 11r18v. 27.05.1599), estos dos últimos pertenecientes a cristianos viejos. 
Tabla 5. Relación de ropas y muebles domésticos más frecuentes en los hogares de moriscos y cristianos viejos. Almagro, 1570-1610

\begin{tabular}{|c|c|c|c|c|c|c|c|c|c|}
\hline \multicolumn{5}{|c|}{ MORISCOS } & \multicolumn{5}{|c|}{ CRISTIANOS VIEJOS } \\
\hline CAT & TIPO & OBJETO & $\mathrm{N}^{\circ}$ & $\%$ & CAT & TIPO & OBJETO & $\mathrm{N}^{\mathrm{o}}$ & $\%$ \\
\hline $\mathrm{RD}$ & $\mathrm{RC}$ & Almohada & 80 & 21,5 & $\mathrm{RD}$ & $\mathrm{RC}$ & Sábana & 469 & 11,8 \\
\hline $\mathrm{RD}$ & $\mathrm{RC}$ & Sábana & 38 & 10,2 & $\mathrm{RD}$ & $\mathrm{RC}$ & Almohada & 367 & 9,2 \\
\hline $\mathrm{RD}$ & OR & Paño & 29 & 7,8 & $\mathrm{RD}$ & $\mathrm{RB}$ & Mantel & 266 & 6,7 \\
\hline $\mathrm{RD}$ & $\mathrm{RC}$ & Delantera & 20 & 5,4 & $\mathrm{MD}$ & $\mathrm{AL}$ & Arca & 228 & 5,7 \\
\hline $\mathrm{MD}^{*}$ & DO & Colchón & 16 & 4,3 & $\mathrm{RD}$ & $\mathrm{RC}$ & Delantera & 209 & 5,3 \\
\hline $\mathrm{RD}$ & $\mathrm{RB}$ & Mantel & 16 & 4,3 & $\mathrm{MD}$ & $\mathrm{OM}$ & Mesa & 173 & 4,3 \\
\hline $\mathrm{RD}$ & OR & Almohada de asiento & 12 & 3,2 & $\mathrm{MD}$ & DO & Colchón & 156 & 3,9 \\
\hline $\mathrm{RD}$ & $\mathrm{RB}$ & Toalla & 12 & 3,2 & $\mathrm{RD}$ & OR & Paño & 145 & 3,6 \\
\hline RD & OR & Pañuelo & 11 & 3,0 & $\mathrm{RD}$ & $\mathrm{RB}$ & Toalla & 118 & 3,0 \\
\hline RD & $\mathrm{RC}$ & Colcha & 9 & 2,4 & $\mathrm{MD}$ & $\mathrm{OM}$ & Silla & 111 & 2,8 \\
\hline $\mathrm{MD}$ & $\mathrm{DE}$ & Alfombra & 8 & 2,2 & $\mathrm{MD}$ & DO & Cama & 101 & 2,5 \\
\hline $\mathrm{RD}$ & $\mathrm{RC}$ & Frezada & 7 & 1,9 & $\mathrm{RD}$ & OR & Tendido & 100 & 2,5 \\
\hline MD & $\mathrm{AL}$ & Arca & 6 & 1,6 & $\mathrm{RD}$ & $\mathrm{RC}$ & Frezada & 96 & 2,4 \\
\hline $\mathrm{RD}$ & $\mathrm{RC}$ & Acerico & 6 & 1,6 & $\mathrm{MD}$ & $\mathrm{OM}$ & Banco & 69 & 1,7 \\
\hline $\mathrm{RD}$ & $\mathrm{RC}$ & Cabecera de cama & 6 & 1,6 & $\mathrm{RD}$ & $\mathrm{RC}$ & Paño de cama & 69 & 1,7 \\
\hline $\mathrm{RD}$ & OR & Poyal & 6 & 1,6 & $\mathrm{MD}$ & $\mathrm{OM}$ & Escabelete & 58 & 1,5 \\
\hline RD & OR & Tendido & 6 & 1,6 & RD & RB & Servilleta & 57 & 1,4 \\
\hline MD & $\mathrm{DE}$ & Espejo & 5 & 1,3 & $\mathrm{MD}$ & $\mathrm{OM}$ & Candil & 56 & 1,4 \\
\hline $\mathrm{RD}$ & $\mathrm{RC}$ & Cercadura de cama & 5 & 1,3 & $\mathrm{MD}$ & $\mathrm{AL}$ & Cofre & 51 & 1,3 \\
\hline RD & $\mathrm{RC}$ & Cobertor & 5 & 1,3 & $\mathrm{RD}$ & OR & Pañuelo & 50 & 1,3 \\
\hline
\end{tabular}

* En sombreado mobiliario.

Clave leyenda: CAT (categoría). RD: ropa doméstica; MD: mobiliario doméstico. Tipo: RC: ropa de cama; RB: ropa blanca (cocina y aseo); OR: otra ropa; AL: muebles de almacenaje; DO: muebles de dormitorio; DE: muebles y objetos decorativos; OR: otra ropa.

Fuente: AHP CR. Protocolos (Almagro), 1570-1610.

Lo que a todos los efectos constituye un factor discrepante es la presencia de la cama. Su uso fue habitual en ambos colectivos, pero siempre en mayor medida en el caso de los cristianos viejos ${ }^{67}$. En esta ocasión el factor de discordancia es el precio. Véase el caso de Almagro. La más cara de cuantas se

67. Incluso en Alcaraz, donde ya se ha visto que el modelo se aparta un poco de la tónica general. Allí la propiedad de este mueble alcanzó a un 72,7\% de las familias de granadinos documentadas (8 de 11) mientras que en el caso de los cristianos fue ligeramente superior (75\%; 63 de 84$)$. 
incluyeron en las dotes moriscas es la que perteneció a Luis de Narváez y a Florencia de Carmona, de madera, tasada en apenas treinta reales ${ }^{68}$. Por su parte, la más valorada en cristianos viejos alcanzó los 855 . Sin duda, la madera dorada del armazón debió ser suficiente para incrementar su valor, aunque es necesario señalar que también influyó la tasación conjunta del mueble junto con algunas de las ropas que le acompañaban ${ }^{69}$. He ahí otra de las distorsiones que se han observado: los moriscos privilegian en sus dotes la inclusión de artículos de cama y superan ampliamente a los cristianos viejos en ese sentido (tabla 5), pero el precio de lo inventariado es inferior por norma general dado que damascos, brocados, sedas y demás aderezos fueron raros en los granadinos. A ello cabe unir el hecho de que los cristianos viejos apostasen por realizar una inversión también mayor en todo lo que se refiere a los muebles de cama propiamente dichos (armaduras, cordeles, bancos y tablas...) y no tanto en relación al simple colchón, como ocurre en el caso de los granadinos.

Finalmente, puede señalarse como nota distintiva -posiblemente la más destacable en esta categoría- la que afecta a mesas, sillas, bancos, veladores, escabeles y demás mobiliario. Su presencia es un hecho contrastado en los hogares rurales del siglo XVI, aunque aún resultaba escasa en los grupos sociales con menos músculo económico. En todo caso, esa no es razón suficiente para explicar el escaso atractivo que este tipo de enseres despertó entre los moriscos. No en balde, y aunque se dan ejemplos en los que se hace uso de ellos, su propiedad no estuvo ni mucho menos generalizada hasta tal punto que puede decirse que no fueron frecuentes en el universo material cristiano-nuevo; ni tan siquiera en el caso de las familias que gozaron de una posición económica equiparable a la de sus vecinos cristianos viejos. No en vano, las fuentes confirman la existencia de una pauta de comportamiento contraria al empleo del mobiliario al uso y que, en cierto modo, puede rastrearse desde los tiempos de la conversión, tal y como lo detectaron en su día Fernández Chaves y Pérez García ${ }^{70}$ tras examinar las cartas nupciales de las moriscas que residieron en el reino de Granada con anterioridad a la guerra de las Alpujarras.

\section{ROPA DOMÉSTICA}

La ropa del hogar es la última categoría que consideramos en nuestro análisis. Frente al mobiliario y al menaje constituye el grupo en el que las diferencias entre ambos grupos se inclinan a favor de los primeros (tabla 3). También aquí, la vivienda morisca se muestra más pobre, más monótona.

Si se profundiza en el análisis, puede observarse que el comportamiento mostrado por nuevos y viejos cristianos difiere en función de los objetos que em-

68. AHP CR. Protocolos, leg. 1611, s.f. 01.07.1606.

69. AHP CR. Protocolos, leg. 1824/2, s.f. 13.03.1610.

70. M. F. Fernández Chaves y R. M. Pérez García, «Las dotes de las moriscas...», p. 188. 
plean en uno u otro ámbito de la actividad cotidiana. En ese sentido, ambas comunidades manifiestan prácticas similares en lo relativo a la ropa blanca (mesa y aseo), aunque Alcaraz y Almagro presentan listados menos diversificados y con un peso cualitativo también menor que Ciudad Real. Sin embargo, y como se ha señalado, el verdadero factor de separación reside en el empleo que se dio a la ropa de cama. La tendencia es general y, aquí sí, afecta por igual a las tres localidades estudiadas, aunque, nuevamente, existen matices entre el medio urbano (Ciudad Real) y los entornos semi-rurales, donde se atenúan algo.

Cabe señalar también la mayor importancia que adquiere el grupo de "otra ropa" en el caso de los granadinos. En este caso concreto, y igual que ocurre con el resto de categorías, las piezas inventariadas (paños, pañuelos, almohadas de asiento, poyales, bancales...) no son muy distintas, pero sí la frecuencia con la que aparecen, siempre mayor que en los cristianos viejos. En realidad, no estamos ante distancias insalvables (en Ciudad Real es de dos puntos y de 1,4 en Almagro) ${ }^{71}$; es más, las cifras indican que la inclusión de cojines, almohadones y demás prendas de acomodo, fue algo habitual en las dotes castellanas. No estamos, pues, ante elementos de raíz específicamente musulmana, aunque sí puede decirse de ellos que fueron utilizados en mayor medida por este colectivo. Distinta cuestión es averiguar qué motivaciones estuvieron en la raíz de esas divergencias. En ese sentido, Isabel dos Guimarães introduce en el análisis de su uso la variable de género en tanto que liga la presencia de este tipo de enseres a los espacios domésticos femeninos ibéricos. Para ella, no habría una componente específicamente morisca ni una vinculación concreta y determinada con el mundo musulmán, sino que su empleo formaría parte de una particular forma (la ibérica) de entender los espacios privados, en la que la mujer haría uso preferente de estos artículos, mientras que el empleo del mobiliario propiamente dicho estaría asociado más a los ámbitos masculinos ${ }^{72}$.

Partiendo de esa base, puede pensarse que el universo morisco apenas si constituye una variable más del entorno hispánico. Se trata de una propuesta sumamente atractiva, pero implica admitir la existencia de un sustrato común a toda la península ibérica y, en cierto modo, minimiza la existencia de especificidades y de influjos procedentes de otros ámbitos culturales. De cualquier forma, tampoco es incompatible con otro tipo de explicaciones tocantes a la minoría, incluso con la existencia y puesta en valor de esas influencias externas a las que nos referíamos. De hecho, hay toda una serie de elementos que, incluso, refuerzan el razonamiento de la autora mencionada. Entre ellos el hecho de que aparezcan indistintamente en las viviendas de uno y otro grupo, pero siempre de manera preferente en las dotes (y no en las arras), así como la im-

71. En Alcaraz son favorables a los cristianos viejos debido a la llamativa escasez de este tipo de objetos que se dan en las dotes moriscas, limitada a una única almohada de asiento.

72. I. DOS GUIMARÃES SÁ, «Habitar: del espacio a los objetos», en M. García Fernández (dir.), Cultura material y vida moderna: escenarios, Madrid, Sílex, 2013, p. 125. 
portancia que el interior doméstico tuvo como marco de sociabilidad y desarrollo de las tareas cotidianas femeninas.

Las diferencias a las que ya hemos hecho referencia también invitan a considerar el ascendiente musulmán, dado que con anterioridad a la guerra de 1568-1570 estas prendas constituyeron un elemento realmente importante en los hogares de los moriscos granadinos, bien fuera siguiendo las decoraciones autóctonas, bien incorporando elementos de tradición castellana ${ }^{73}$.

Para terminar, también conviene detenerse en los aspectos de orden cualitativo. De entre ellos, el principal es el relativo al empleo de textiles. Su relevancia en los ajuares es vital, especialmente en aquellos pertenecientes a individuos encuadrados en los grupos populares ${ }^{74}$. Al igual que ocurre con otras características como el color, el estado de conservación o la procedencia de los géneros, la materia prima no siempre se indica. En el caso analizado, esa situación ha alcanzado a prácticamente la mitad de las prendas contabilizadas, lo cual no ha impedido disponer de una muestra relativamente sólida (gráfico 3).

Nuevamente, y a raíz del conjunto analizado, ha podido constatarse que los moriscos emplearon una gama de productos y géneros más limitada y humilde a lo que se une una generalizada adaptación a los tejidos "de la tierra". La expresión, muy esclarecedora a nuestro juicio, es especialmente habitual en los inventarios nupciales de Alcaraz ${ }^{75}$ y lleva a considerar la importancia de los factores de orden económico y geográfico, entre los que la adquisición de productos locales y comarcales debió ser la tónica predominante.

La inclinación por los lienzos es abrumadora, mayor incluso que en los cristianos viejos. Dentro de ellos, lino y cáñamo copan las preferencias de ambos grupos, pero todo indica que, posiblemente por una cuestión de precio, los moriscos minimizaron la presencia del primero en beneficio de otros géneros más baratos. En todo caso, esa situación no impide comprobar que el propio

73. M. F. Fernández Chaves y R. M. Pérez GarcíA, «Las dotes de las moriscas...», p. 138 y L. RAMÓN-LACA MENÉNDEZ DE LUARCA, «De cómo vivían los moriscos en sus casas», en VIII Simposio Internacional de Mudejarismo. De mudéjares a moriscos: una conversión forzada. Teruel 15-17 de septiembre de 1999. Vol. II, Teruel, Centro de Estudios Mudéjares (Instituto de Estudios Turolenses), 2002, p. 767.

74. Así lo ponen de manifiesto M. GARCía Fernández y R. M. a Dávila Corona en «El consumo de productos textiles en Valladolid: 1750-1850», Investigaciones Históricas: Época moderna y contemporánea, 21, 2001, pp. 133-180, p. 146. Aunque es una cuestión a la que se ha prestado mucha atención en trabajos relativos al siglo XVIII (por el interés en desentrañar las peculiaridades del proceso de industrialización y el abandono del taller tradicional) está sensiblemente, pero peor analizada para el XVI y el XVII, más aún en el caso de la minoría morisca. Para el Seiscientos en Castilla resulta muy acertado el trabajo ya citado de F. ZARANDIETA ARENAS acerca de la Baja Extremadura en el siglo XVII.

75. Por ejemplo, y entre otros, en el paño de cama "desta tierra" de Isabel Ruiz y más allá de la ropa doméstica, en el vestido "de paño de la tierra" que perteneció a María de las Eras, ambas moriscas de Alcaraz. AHP Ab. Protocolos, leg. 1150/1, ff. 66r-68v. 20.02.1609 y leg. 1134/3, ff. 35r-36r. 23.01.1599. 
lino fue mucho más habitual en las ropas blancas (manteles, servilletas, paños de mesa...), precisamente donde los moriscos invierten menos dada su predilección por las de cama, en cuya factura ese género comparte protagonismo con el cáñamo y el ruan.

Gráfico 3. Empleo de textiles en la ropa doméstica de moriscos y cristianos viejos. Alcaraz, 1570-1610*

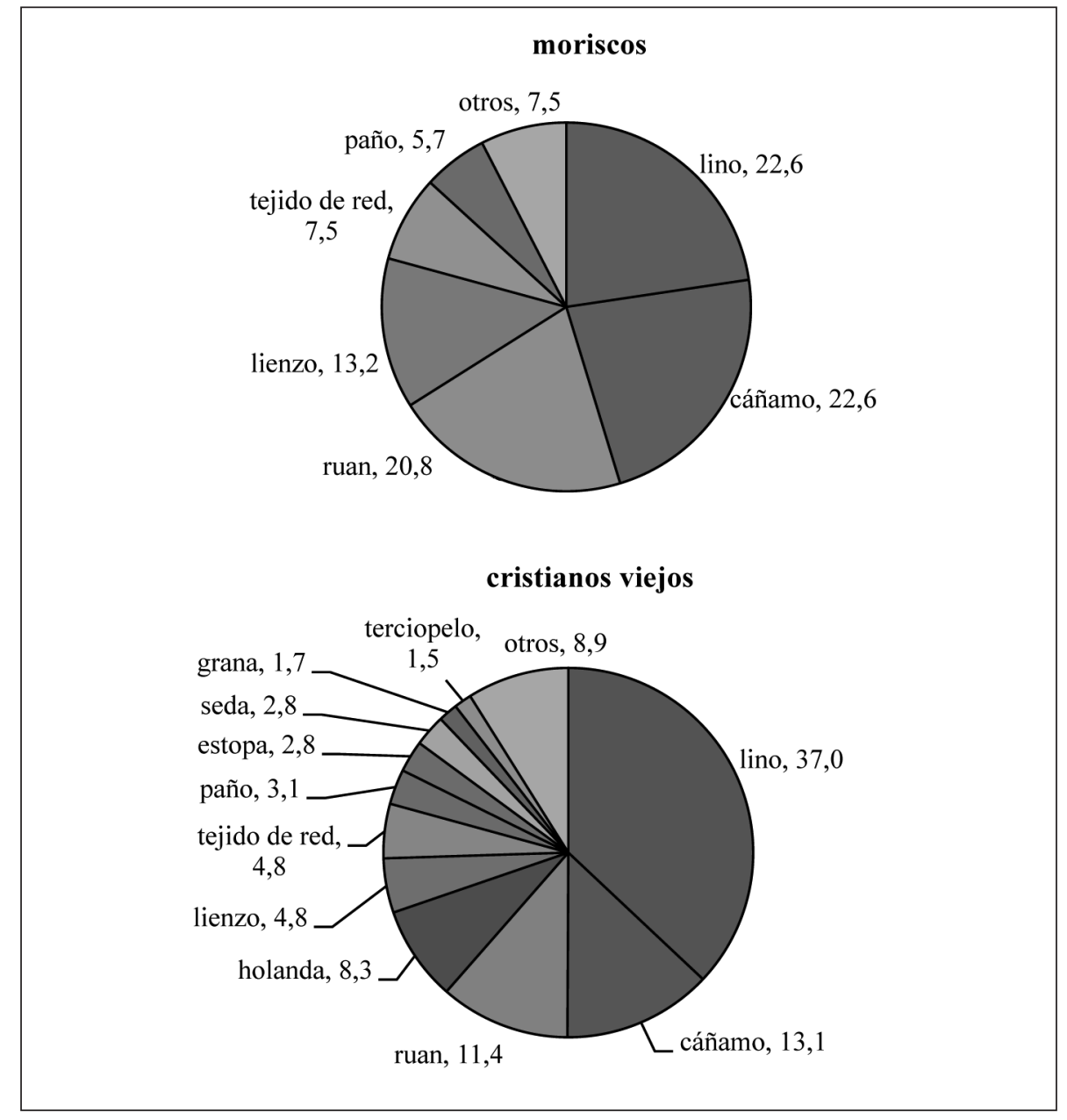

* Muestra: artículos en los que se especifica materia prima: 601 de 1252 -48\%- en el caso de los cristianos viejos; 53 de 105 -50,4\% - en moriscos. Categoría "otros": moriscos: 4 géneros; cristianos viejos: 52. Fuente: AHP AB. Protocolos. Alcaraz. Diversos legajos (1570-1610). 
Por lo que respecta al resto de tejidos cabe señalar la práctica ausencia de algodones y la escasa representatividad de las sedas. De la inclusión de estas últimas en las dotes del reino de Granada dijeron Chaves y Pérez que constituyó una verdadera inversión en la principal industria del país ${ }^{76}$, pero lo cierto es que esos mismos autores confirman su decadencia una vez pasada la guerra. Su constatación, relativa a Sevilla, es perfectamente aplicable al caso manchego (gráfico 3), donde dicha materia prima no fue habitual ni en los cristianos viejos. Tanto fue así que su uso en el hogar quedó apenas limitado a constituir un acompañamiento al tejido principal de algunas prendas (sábanas y cabeceros principalmente) o a los bordados (labrados).

Finalmente, hay que hablar de las decoraciones. En realidad, nos situamos ante un aspecto que conviene plantear con cautela porque los bordados, brocados, randados y encajes... incluso la introducción de diferentes tejidos en una misma pieza no es algo ni mucho menos específico de la realidad morisca. Ocurre, además, que es una cuestión cuyo análisis entra más en el campo de lo cualitativo al depender también, y entre otras cosas, de la información que los inventarios ofrecen.

Así, el término "a la morisca" es empleado con cierta asiduidad para describir lo que debió ser una particular forma de componer tejidos, aunque su empleo también se extendió más allá de la ropa doméstica y no solo se documenta en los ajuares de los granadinos ${ }^{77}$. No obstante, la aparición de objetos que pudieran resultar específicamente moriscos en su presentación no está reñida con la presencia de textiles de tradición castellana. Ese proceso de simbiosis y la incorporación de elaboraciones de diversa procedencia debieron ser un hecho hasta el punto de que, en ocasiones, puede resultar complicado deslindar dónde empieza una influencia y donde acaba otra.

Sin embargo, sí puede decirse que las prendas analizadas parecen desprender una impronta particular, en la que, a pesar de ello, no se detecta una pauta

76. M. F. Fernández Chaves y R. M. Pérez García, «Las dotes de las moriscas...», p. 136.

77. Su aparición es habitual y su reflejo en la documentación, incluso, anterior a la etapa morisca propiamente dicha tal y como ha demostrado J. Aparici a raíz del estudio de inventarios pertenecientes a mudéjares de Castellón. Véase J. APARICI MARTí, «Bienes muebles de mudéjares castellonenses. Siglo XV», Sharq al-Andalus, 19, 2008-2010, p. 89. En torno a este asunto resulta todavía imprescindible el trabajo, ya clásico, de C. BERNIS, «Modas moriscas en la sociedad cristiana española del siglo XV y principios del XVI», Boletín de la Real Academia de la Historia, 144, 1959 , pp. 199-218. Por lo demás, la aparición de dicho concepto en bienes pertenecientes a cristianos viejos podría llevarnos a hablar de un proceso de transferencia cultural y de imitación y asunción de modas que afectó a ambos grupos y que, más allá de estas líneas, merecería una aproximación específica. Por ejemplo, en Alcaraz - una vez más la nota discordante- todos los objetos que se han documentado con esta factura pertenecen a cristianos viejos y aunque mayoritariamente se ligan a artículos domésticos, la decoración "a la morisca" también se encuentra presente en joyas y vestimentas femeninas. En relación con ello véase F. J. MORENO DÍAZ DEL CAMPO, «El hogar morisco...», pp. 115-116. También y en lo relativo al vestido I. LASMARÍAS PONZ, "Vestir al morisco, vestir 'a la morisca': el traje en Aragón en la Edad Moderna", en Actas del X Simposio Internacional de Mudejarismo, Teruel, Centro de Estudios Mudéjares (Instituto de Estudios Turolenses), 2007, pp. 629-641. 
ornamental común, sino que esta depende más bien de la combinación de motivos, tejidos y colores. En lo tocante al hogar, es frecuente encontrar el concepto asociado a todo tipo de artículos y para referirse a decoraciones variadas, en las que una de las notas predominantes es la presencia de una gama cromática amplia $^{78}$. Fuera de esa constatación no hay más matices y las características apuntadas se extienden al resto de grupos que se han definido (tabla 3): cabeceros de cama "labrados a la morisca" "79; sábanas "moriscas" ${ }^{80}$; traveseros "llanos" ${ }^{81} \mathrm{o}$ "con borlas" ${ }^{82}$; almohadas también labradas de color azul, verde, negro y colorado "y de otros colores" ${ }^{83}$, pasando por cojines ${ }^{84}$ y almohadas de asiento ${ }^{85}$; paños listados ${ }^{86}$; manteles vareteados de azul ${ }^{87}$... La factura, composición y remates que se han documentado son de lo más diverso, multiplican los ejemplos y admiten cientos de combinaciones en las que solo merecería la pena seguir insistiendo para reforzar esa imagen de diversidad, que no es extraña en otros ámbitos geográficos y que confirió una particular (¿y específica?) impronta que, parece, pudo conservarse hasta el momento mismo de la expulsión, ya que hay ejemplos fechados apenas unas semanas antes de los bandos.

\section{CONCLUSIONES}

Constituye casi un tópico afirmar que la guerra de las Alpujarras supuso un punto de inflexión para los moriscos, pero no cabe duda de que los cambios y transformaciones a los que tuvieron que hacer frente los granadinos alcanzaron a prácticamente todas las esferas de su existencia. La ruptura de los patrones de comportamiento previos a la propia contienda fue un hecho desde el mismo momento en que los vencidos se instalaron en Castilla. Tanto fue así que los cuarenta años que mediaron entre 1570 y 1610 pueden ser individualizados como una etapa más de la particular historia de los antiguos moros de Granada. Debido a los cambios que el destierro llevó consigo, el asunto morisco trasladó

78. Somos de la opinión de que en ello hay un indudable sesgo cultural. En torno a estas cuestiones, y en un sentido muy similar, véase M. F. FERnÁndez ChAVES y R. M. PÉrez GARCÍA, «Las dotes de las moriscas...», pp. 135-136.

79. AHP CR. Protocolos, leg. 1614, s.f. 17.10.1600.

80. AHP CR. Protocolos, leg. 2008/1, ff. 494r-497v. 22.01.1585.

81. AHP CR. Protocolos, leg. 53/1, ff. 17r-19r. 01.02.1595.

82. AHP CR. Protocolos, leg. 54, ff. 22r-25v. 28.01.1594 y leg. 54bis, ff. 208r-210r. 29.10.1595.

83. AHP CR. Protocolos, leg. 75, ff. 284r-286r. 06.02.1600.

84. Por ejemplo, Lucía de Segura llevó en su dote seis almohadas de asiento bordadas de diferente manera, de las cuales cuatro eran azules, una de colores y otra amarilla. AHP CR. Protocolos, leg. 54, ff. 6r-8r. 02.01.1594

85. AHP CR. Protocolos, leg. 75bis/2, ff. 354r-356v. 08.12.1600.

86. AHP CR. Protocolos, leg. 30bis / 4, ff. 1r-4r. 03.11.1589 y leg. 1824/1, s.f. 15.06.1578, entre otros.

87. AHP CR. Protocolos, leg. 80/1, ff. 284r-287v. 10.05.1609. 
su epicentro a Castilla. La incidencia de dicho fenómeno es sobradamente conocida; como también lo son muchas de las vertientes en que dichas transformaciones se manifestaron. En adelante, el comportamiento económico de la minoría no sería el mismo; tampoco sus formas de religiosidad, ni las relaciones que sus miembros mantuvieron con los cristianos viejos $\mathrm{y}$, ni mucho menos, el sometimiento a las autoridades de la Monarquía Hispánica. Todo, absolutamente todo, fue objeto de cambio y transformación.

Entre esas mutaciones también se cuentan las que afectaron al mundo de lo cotidiano. Estamos ante un aspecto poco tratado aún, pero que bajo nuestro punto de vista reviste una importancia capital. No en balde, el desenvolvimiento material de cualquier grupo humano (sea el que sea) dice mucho acerca de las condiciones en que ese colectivo vive. No solo es reflejo de su cotidianeidad, sino que revela su esencia y contribuye a definirlo.

Es mucho todavía lo que queda por saber acerca de la realidad cotidiana de los moriscos granadinos afincados en Castilla con posterioridad al conflicto alpujarreño. La historiografía ha dado importantes pasos en ese sentido y poco a poco se va conociendo más acerca del particular. Las líneas que ahora se cierran fueron concebidas como un intento de arrojar algo de luz acerca del particular universo material de los moriscos. Dentro de ese ámbito, la casa constituye uno de los aspectos menos conocidos. En parte, ello es debido a que tampoco fue foco de atención preferente por parte de la Corona. De hecho, fue un aspecto de la cotidianeidad morisca que generó poca preocupación y que, por lo tanto, encontró poco eco en la legislación castellana del momento. El hecho de permanecer relativamente al margen de la presión cristiano-vieja, facilitó que el morisco buscase configurar un espacio en que aislarse de la presión exterior y que, en la medida en que ello fue posible, intentase trasladar a ese marco su propio bagaje cultural.

Por eso el hogar morisco de Castilla fue epicentro de un proceso de hibridación cultural. Evidentemente, esa evolución estuvo marcada por el mantenimiento de las formas exteriores castellanas y el respecto a las normas de comportamiento socio-cultural dictadas por la burocracia filipina, pero no se olvidó de mantener todo cuanto fue posible de la herencia cultural islámica. En ese contexto, y según vamos conociendo, la casa morisca de Castilla no fue igual a la de Granada ni en lo referido a su arquitectura ni en lo relativo a su atmósfera material. En su configuración pesaron casi a partes iguales tanto los factores de orden económico como los culturales. Sin lugar a dudas, los primeros justifican la existencia de más o menos conceptos en una misma dote y sirven para contextualizar las posibilidades que hubo de que una familia cualquiera pudiera disponer de un hogar más diversificado. Sin embargo, la riqueza no es suficiente para explicar la ausencia (o presencia) de determinados objetos cuyo valor no fue excesivo, pero que, quizás, no fueron concebidos como necesarios en el modelo de vivienda que los moriscos aspiraban a construir. Esos artículos pertenecieron en su inmensa mayoría al moblaje y en muchas 
ocasiones fueron relegados a un segundo plano en aras de favorecer el mantenimiento y utilización de otros, los cuales representaron un evidente nexo con la tradición cultural perdida tras la guerra.

No en vano, el destierro obligó a los moriscos a redefinir el papel que la casa había jugado hasta ese momento. En ese sentido, la llegada a Castilla incorporó al marco relacional de los granadinos un nuevo espacio: la calle ${ }^{88}$, entendida como prolongación del hogar y en el caso de los propios cristianos nuevos como escenario en el que demostrar la pretendida (¿y fingida?) ortodoxia que las autoridades y cuerpo social castellano esperaban de los vencidos. Es ahí donde cabe volver al concepto con el que se iniciaban estas breves conclusiones y aceptar que a partir de 1570 ese mismo hogar mantiene su función como marco de sociabilidad informal privada, pero que también se transforma y se define como un espacio construido desde una posición de subordinación social (incluso de sometimiento económico) en el que el propio morisco aspira no solo a vivir, sino a convivir con su comunidad y a mostrarse tal cual es y siente que debe ser.

\section{RESUMEN}

La llegada de los moriscos granadinos a Castilla después de la guerra de las Alpujarras conllevó un cambio radical en sus costumbres y dio lugar a una nueva forma de afrontar la realidad cotidiana.

El artículo que sigue intenta analizar cómo esas transformaciones alcanzaron también al hogar y a las formas de vida cotidiana desarrolladas en el espacio privado. Para ello ha analizado el comportamiento de algunas de las más importantes comunidades de moriscos granadinos que se instalaron en Castilla la Nueva. Los resultados de dicho análisis se han comparado con los relativos a cristianos viejos y han permitido comprobar que los moriscos adaptaron su comportamiento material al tiempo que intentaron preservar su identidad como grupo. El objetivo perseguido fue construir en el hogar un espacio refugio, en el que familia y comunidad encontraron un marco de sociabilidad específico y propio, alejado de las formas materiales y relacionales castellanas.

Palabras clave: moriscos, cultura material, hogar, protocolos notariales, Castilla, siglo XVI, asimilación.

88. En torno a esta idea J. IVARS PÉREZ, «Unas viviendas moriscas...», pp. 91-101. 


\section{ABSTRACT}

The arrival of the Moriscos of Granada to Castile after the Rebellion of the Alpujarras implied a radical change in their habits and traditions and leaded to new ways of facing every day's routine.

This paper aims to analyse all those changes in a particular scenario: a home, where Moriscos developed most of their private forms of lifestyle. In order to know more about these aspects, some of the most important Morisco communities settled in New Castile after 1570 have been examined. The results of this analysis have been compared to the ones related to the Cristianos Viejos. The obtained data has allowed us to observe how Moriscos adjust their material behaviour, trying to preserve their cultural particularities and their collective identity. Their main immediate purpose was to build their homes as a refuge against the pressure applied by the Castilian society and authorities in order to protect themselves.

Key words: Moriscos, material culture, home, notary's protocols, Castile, Sixteenth century, assimilation. 